\title{
Conectividad en la Edad del Bronce del occidente de la península ibérica. Examinando la relación entre sitios y vías pecuarias mediante SIG*
}

\author{
Connectivity in Bronze Age Western Iberia. Appraising the relationship between sites and \\ droveways using GIS
}

\author{
Antonio Blanco González ${ }^{\mathrm{a}}$ Ángel Esparza Arroyo
}

\section{RESUMEN}

Este artículo evalúa de forma crítica una vieja hipótesis de la Prehistoria de la península ibérica que ha quedado sin refutar: la que relaciona los sitios de Cogotas I (1850-1100 cal AC) con la trashumancia. Se propone un experimento en una amplia franja del occidente ibérico coincidente con la denominada Vía de la Plata: la medición con SIG de la distancia lineal entre 176 sitios de Cogotas I y las vías pecuarias, concebidas como síntomas materiales de hábitos inveterados. Los resultados, estadísticamente significativos con matices regionales, indican que casi un tercio de los casos -el 27,3\%- se encuentran a menos de $500 \mathrm{~m}$. Evitamos relacionar esa proximidad con la trashumancia, la subordinación centro-periferia o el tráfico de objetos elitistas. Entendemos tal pauta como indicio del interés de los grupos estudiados, entre otras decisiones locacionales, por participar en la circulación de personas, animales y cargas, conforme al modelo de comunidades políticas paritarias (peer polity interaction).
Spatial analyses are statistically significant in the Duero sector yet non-significant in Extremadura due to its incomplete dataset; overall they point out that almost a third of the sites -27.3\%-are located less than $500 \mathrm{~m}$ from any such route. The authors avoid linking this observation to transhumance, centre-periphery dynamics, social hierarchy or prestige good economies. Instead, they frame these results within the model of peer polity interaction between local communities aiming to connect with each other in their social landscape, thus participating in the circulation of people, animals, and items.

Palabras clave: Movilidad; Sistemas de Información Geográfica; Análisis exploratorio de datos; Vías pecuarias; Península ibérica; Cogotas I; Edad del Bronce.

Key words: Mobility; Geographic Information Systems; Exploratory data analysis; Droveways; Iberian peninsula; Cogotas I Culture; Bronze Age.

\section{INTRODUCCIÓN}

La movilidad de personas y animales y el trasiego de objetos acabados y materias primas están de actualidad en la Prehistoria mediterránea (Celestino et al. 2008; Ruiz-Gálvez 2013; Murrieta-Flores 2014; Souvatzi y Hadji 2014; Yubero-Gómez et al. 2015; Pavón et al. 2018). En la península ibérica nunca ha dejado de hablarse de contactos, trashumancia, influencias e

* Investigación enmarcada en el proyecto de I+D+i de Excelencia "Recursos, dieta y movilidad en las poblaciones del Grupo Cogotas I" (HAR201343851-P) financiado por el Ministerio de Economía y Competitividad (IP: Ángel Esparza/Germán Delibes).

a Grupo de Investigación Reconocido (GIR) Estudios de Prehistoria de la Península Ibérica (PREHUSAL), Dpto. de Prehistoria, Historia Antigua y Arqueología. Universidad de Salamanca. C/ Cervantes s/n. 37002 Salamanca. España. Correo e.: ablancoglez@usal.es https://orcid.org/0000-0003-4502-9651.

b Instituto de Estudios Zamoranos ‘Florián de Ocampo'. Correo e.: esparza@usal.es https://orcid.org/0000-0002-9139-0774

Recibido 26-II-2018; aceptado 22-X-2018. 
intercambios, a menudo de forma demasiado ambigua (Díaz-del-Río 2001: 83). La bibliografía distingue entre la trashumancia de larga distancia $(>100 \mathrm{~km})$, que requiere una logística y condiciones materiales propias de los estados modernos, y la trasterminancia de corto-medio alcance (unas decenas de $\mathrm{km}$ ) o de complementariedad llano-montaña, practicada a escala restringida para diversificar el pastoreo según su disponibilidad altitudinal y estacional (Galaty y Johnson 1990; Greenfield 1999). Además, la literatura ha asumido dos factores explicativos no exentos de problemas. El primero deriva de incluir la península ibérica en ciclos de intercambio centro-periferia a escala macrorregional o continental (Ruiz-Gálvez 1993, 1998, 2013). Una lectura poco cautelosa de ese planteamiento ha llevado a entender esas fuerzas externas y la inercia de las superestructuras comerciales como motores de los cambios en las sociedades oriundas (p. e. Celestino 2001). Se ha criticado tal visión (Gilman 1993: 108-109; Delgado 2013) por relegar a las comunidades locales al papel de intermediarias dependientes, socialmente retardatarias pero insertas siempre en economías de bienes de prestigio. En segundo lugar, se ha considerado la actividad ganadera como principal y casi exclusivo medio de vida entre muchos de esos grupos mediadores (p. e. Harrison 1994; MurrietaFlores 2014), así como una vía factible para financiar sus comportamientos elitistas. Tal especialización pudiera ser plausible durante el II milenio AC, pero su argumentación debería prescindir de estereotipos atemporales, cargados de determinismo ambiental, y justificarse caso por caso, en condiciones históricas contingentes (Barker 1985; Horden y Purcell 2000; Mlekuž 2005; Walsh 2014).

Entre las líneas de trabajo desarrolladas en el ámbito peninsular sobre la movilidad y los intercambios, las rutas terrestres $-\mathrm{y}$ las fluviales y marítimas, más importantes pero peor estudiadas- por las que circularon gentes y animales, han acaparado enorme interés (Ruiz-Gálvez 1998). Dejando aparte su estudio en la Protohistoria (p. e. Esparza 1999: 95-98, hasta los años 1990 tres fenómenos de la Prehistoria Reciente peninsular concentraron las discusiones sobre los caminos de comunicación interior (Sánchez Moreno 1998: 5861): a) el megalitismo del IV milenio AC; b) la expansión de Cogotas I en el II milenio AC; y c) las estelas del suroeste entre finales del II e inicios del I milenio AC. Tras generalizarse la arqueometría, los estudios sobre intercambio y movilidad prehistóricos se han extendido a otras muchas etapas y regiones ibéricas. Pero las discusiones pivotan en torno a esos tres temas clásicos, cuya contribución teórica y práctica ha sido muy desigual. El megalitismo representa el campo más dinámico y fructífero: la crítica anglosajona (Chapman 1979; Walker 1983) desacreditó las analogías actualistas de la trashumancia, basadas en la Mesta moderna (Ruiz Martín y García Sanz 1998). Los trabajos de F. Criado y su equipo en Galicia (Infante et al. 1992; Criado et al. 1990-1991; Criado y Vaquero 1993; Criado 1997) renovaron los planteamientos tradicionales desde un enfoque de Arqueología del Paisaje. Dentro de este asunto, en los últimos años se han ensayado métodos de análisis territorial a escalas micro y meso-espaciales para caracterizar con rigor la relación entre esos monumentos y la caminería histórica: tanto megalitos neolíticos (Fairén et al. 2006; Wheatley et al. 2010; Murrieta-Flores et al. 2011, 2014) como menhires y túmulos algo posteriores (Delibes et al. 2012: 22-27; Rojo-Guerra et al. 2014: 145 148). Le sigue en importancia el problema de las estelas del Bronce Final del suroeste, objeto de controversia sobre los jerarcas supuestamente representados en ellas y el sustento ganadero de su poder (Ruiz-Gálvez y Galán 1991; Galán 1993; Vilaça 1995; Celestino 2001; Rodríguez Díaz y Enríquez 2001; Harrison 2004; Díaz-Guardamino 2010). Este tema sólo recientemente ha suscitado métodos prácticos para confrontar hipótesis, consiguiendo contextualizar el subgrupo de las 'estelas de guerrero' en su territorio (García Sanjuán et al. 2006; Celestino et al. 2011). Un último foco de pesquisa ha sido el hallazgo de cerámicas de Cogotas I fuera del núcleo meseteño, vinculadas a estrategias de itinerancia pastoril. En este caso, la relación entre vías pecuarias y yacimientos ha concitado un intenso escrutinio historiográfico, que ha desacreditado la posibilidad de movimientos de largo recorrido (Fernández-Posse 1998; Ruiz-Gálvez 1998; Jimeno 2001; Abarquero 2005, 2012; Abarquero et al. 2009), pero la hipótesis sigue careciendo de cualquier intento de refutación empírica.

Este trabajo se centra en el caso de Cogotas I, que hasta ahora no se ha beneficiado de las herramientas de análisis territorial. Para ofrecer lecturas críticas desde argumentos alternativos a los tradicionales, el texto abarca temas de difícil deslinde -movilidad, interacción y reciprocidad, estrategias extensivas de pastoreo complementario, intercambio interregional, etc.- desde el concepto flexible e inclusivo de la conectividad del paisaje (Mitrović 2016). Nuestro ensayo aborda la relación espacial entre yacimientos de Cogotas I y la caminería pecuaria tradicional, entendida no como sustituto extemporáneo de la trashumancia, sino como síntoma de prácticas sociales seculares, aún legibles en el paisaje (Fairén et al. 2006). La zona de trabajo elegida es una vasta franja occidental de España articulada por la Vía de la Plata (Fig. 1), uno de los principales y más antiguos ejes de comunicación en Iberia. Acudimos a los Sistemas de Información Geográfica (en adelante SIG) para caracterizar de manera indirecta, pero sistemática, en qué medida los sitios de Co-

Trab. Prehist., 76, N. ${ }^{\circ}$ 1, enero-junio 2019, pp. 67-83, ISSN: 0082-5638

https://doi.org/10.3989/tp.2019.12226 


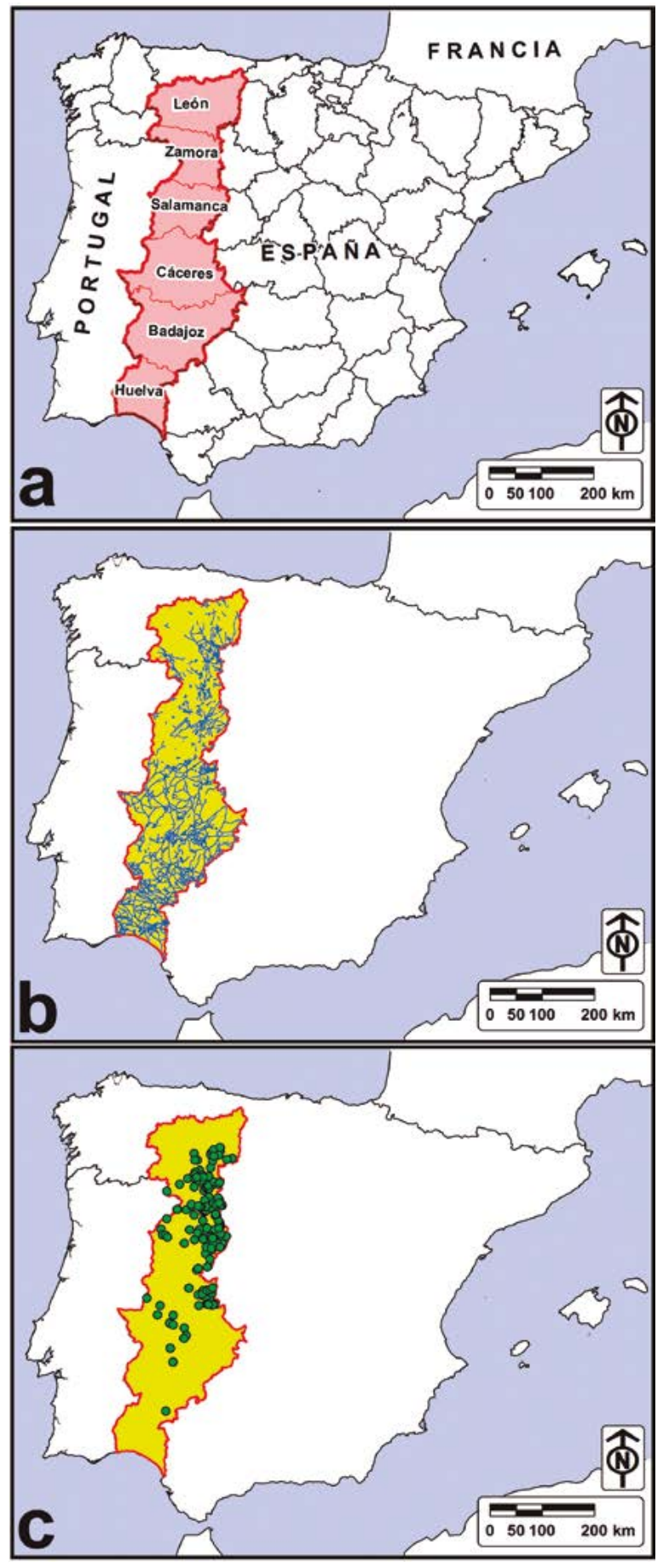

Fig. 1. Localización del área de estudio en la península ibérica: A. Las seis provincias españolas que la comprenden. B. Vías pecuarias analizadas. C. Los 176 yacimientos de Cogotas I (1850-1100 cal AC) considerados (en color en la versión electrónica).

gotas I en el sector estudiado se localizaron próximos a algún tramo de la red viaria ganadera. Finalmente, evaluamos la representatividad estadística de las observaciones logradas frente al puro azar, e interpretamos esas pautas desde el marco sociológico de la interacción entre comunidades políticas paritarias (peer polity interaction) (Renfrew 1986).

\section{TRASHUMANCIA, CONECTIVIDAD E INTERACCIÓN}

La comprensión de los modos de vida del interior peninsular en la Edad del Bronce y, en particular, entre las gentes de Cogotas I (1850-1100 cal AC), ha basculado entre dos polos opuestos (Fernández-Posse 1998: 101-106; Jimeno 2001; Díaz-del-Río 2001: 77 101; Abarquero 2005: 423-437). Tradicionalmente fueron vistos como pastores ambulantes y agricultores de rozas (Delibes y Romero 1992; Blasco 1993: 156). Desde los años 1990 comenzó a pensarse en campesinos primitivos con reses estantes (Harrison 1994; Díaz-del-Río 1995, 2001; Ruiz Zapatero 2007; Delibes y Romero 2011; Blasco 2012).

Desde los primeros mapas peninsulares de distribución de Cogotas I, elaborados a finales de la década de 1970, se sugirió la posibilidad de desplazamientos del ganado para explicar su desigual reparto: un abigarrado foco meseteño y sitios con idénticas cerámicas dispersos en su periferia. Así, un asentamiento en pleno ámbito argárico como la Cuesta del Negro (Purullena, Granada), con abundante vajilla decorada de Cogotas I y en el extremo de una cañada pecuaria hizo pensar en trayectos trashumantes con la Meseta (Molina y Pareja 1975: 55-56). En el seno del equipo granadino, ese planteamiento fue elaborado por Fernández-Posse en su tesis doctoral, donde defendió la propagación peninsular de esta cultura por las rutas del ganado semoviente hasta los invernaderos meridionales ${ }^{1}$ : "Estos caminos del ganado con estancias y aguadas, debieron sin duda de representar un papel cierto en la expansión, desarrollo y dinámica de nuestra cultura. Y coincidirían, además, con puestos de caza y transición que (...) debieron de seguir los mismos caminos de los rebaños de especies domésticas". Hoy día esa muy matizada postura inicial de FernándezPosse ha perdido bastante fuerza. La propia investigadora negó posteriormente la posibilidad de trashumancia (Fernández-Posse 1998: 119), alineándose así con las objeciones de Chapman (1979) sobre la ausencia de estructura jurídica e intendencia. Con tal posición convergieron otros investigadores (Ruiz-Gálvez 1998: 228-234, Fig. 72; Díaz-del-Río 2001: 81 y 285-288;

Fernández-Posse, M. ${ }^{\text {a }}$ D. 1980: El final de la Edad del Bronce en la Meseta Norte: la Cultura de Cogotas I. Tesis doctoral inédita. Universidad de Granada, p. 723. 
Abarquero 2005: 423-437, 2012: 93-94; Blasco 2012: 189; Abarquero et al. 2009) que no consideran plausible la trashumancia ante la nula necesidad de someter al ganado a traslados de tal calibre; las brañas de las serranías que orlan las llanuras meseteñas y los humedales campiñeses habrían facilitado suficientes pastos de veranada. En la actualidad se acepta para Cogotas I un amplio espectro de estrategias agroforestales extensivas (Díaz-del-Río 1995). Tal escenario hace compatibles la permanencia y fijación plurianual de aquellas comunidades con posibles movimientos cortos trasterminantes (Ruiz-Gálvez 1998: 228; Jimeno 2001; Delibes y Romero 2011; Blasco 2012), así como la existencia de individuos que cambiaron de residencia por prácticas exogámicas (Abarquero 2012: 95-96).

Si hay una región peninsular donde se ha insistido, con buenos motivos, en el papel crucial del movimiento ganadero y el trasiego de gentes y materias, esa es la franja occidental por donde discurre la Vía de la Plata (Fig. 1). Antes de la presencia fenicia (1300-900 cal AC) esa banda occidental fue dinámica: menudearon las estelas con tocado, la orfebrería, las fíbulas de codo, algunos asadores y vajilla metálica mediterráneos, armas atlánticas y los primeros hierros 'blandos' (Almagro-Gorbea 1977, 2008; Delibes y Romero 1992, 2011; Ruiz-Gálvez 1993, 1998, 2013; Álvarez-Sanchís 1999: 54-61; Rodríguez Díaz y Enríquez 2001; Celestino et al. 2008; Díaz-Guardamino 2010: 225-291; Álvarez-Sanchís et al. 2016). Tales indicios se han asimilado, de forma unánime, con unas aristocracias locales. Serían las gestoras de las rutas transitadas por arrieros con los ganados, ideas, productos y materias primas (cobre, estaño, sal), intermediarias en transacciones de larga distancia y competidoras entre sí por su control monopolístico (Celestino 2001; Rodríguez Díaz y Enríquez 2001: 119-135; Álvarez-Sanchís 1999: 59; Abarquero 2012: 94).

Sin embargo, lo que vamos sabiendo sobre las sociedades del II milenio AC en la fachada atlántica cada vez encaja peor con ese atractivo relato. Las comunidades locales del Noroeste han quedado relegadas al papel de intermediarias pasivas, en el margen de los sistemas interregionales atlántico y mediterráneo (Rodríguez Díaz y Enríquez 2001: 94-119; Harrison 2004; Almagro-Gorbea 2008), como se ha denunciado (RuizGálvez 1998; Celestino et al. 2008; Delgado 2013). Necesitamos caracterizar mejor las dinámicas internas de esos grupos y conocer sus intereses y los beneficios de participar en tales tráficos (Vilaça 1998; Armada 2013; González Cordero 2015; Rodríguez Díaz et al. 2015). También es cuestionable que el protagonismo local recayera en unos pocos interlocutores, jerarcas bajo demandas e incentivos externos (Álvarez-Sanchís 1999; Celestino 2001; Rodríguez Díaz y Enríquez
2001; Armada 2013). Su visibilidad es esporádica, no generalizable y deberíamos atender mejor a la rica variabilidad sociopolítica en el espacio y tiempo. La vigencia milenaria de esas rutas de intercambio terrestres trasciende los fenómenos de interacción del II milenio AC, que aprovecharon las rutas preexistentes (Ruiz-Gálvez 1993; Almagro-Gorbea 2008; Celestino et al. 2008).

Ante los problemas de esas lecturas históricas y dada la ausencia de estudios territoriales a escala macrorregional, la propuesta original de Fernández-Posse sobre la relación entre los sitios de Cogotas I y la trashumancia conserva parte de su atractivo. Al menos merece ser refutada, pues el intento pudiera ofrecer pistas sobre algunas de las cuestiones hoy discutidas. Aquí retomamos la hipótesis de la trashumancia introduciendo tres correcciones necesarias: a) debe superarse el "pronunciamiento meramente visual" (Chapman 1979: 150) sobre la relación espacial entre puntos arqueológicos y ejes de comunicación; b) habría que insistir en el potencial heurístico de las vías pecuarias como cauce de interacciones sociales más allá de la analogía débil con la Mesta moderna; y c) la proximidad entre sitios y caminería pastoril tradicional no prueba ningún tipo concreto de actividad (trashumancia, comercio) ni un modelo apriorístico de organización sociopolítica (comunidades jerárquicas y economía de bienes de prestigio).

Respecto al primer punto, los primeros ensayos de análisis espacial entre rutas tradicionales y lugares prehistóricos en Iberia (p. e. Infante et al. 1992; Criado et al. 1990-1991; Criado y Vaquero 1993) recurrieron a métodos que hoy se considerarían rudimentarios. Cualquier experimento sobre problemas locacionales debe formalizar sus observaciones y hacer explícita su incertidumbre (Murrieta-Flores et al. 2011, 2014). Las herramientas SIG cumplen tales requisitos, y por eso recurrimos a ellas.

En segundo lugar, las vías pecuarias son un resultado acumulativo, multitemporal y diacrónico, fruto de una larga experiencia desde tiempos prehistóricos (Ruiz-Gálvez 1999; Almagro-Gorbea 2008; Díaz-Guardamino 2010). Los geógrafos han caracterizado la génesis remota de la red de cañadas de la Mesta, definitivamente institucionalizadas por Alfonso X en 1273 (García Martín 1991; Fairén et al. 2006: 57-59). Así, Cabo Alonso (1994a, 1994b) enfatiza una inveterada lógica en la conducta humana: la de los cazadores siguiendo los desplazamientos anuales de herbívoros salvajes. Tales movimientos vendrían condicionados por factores naturales: el fuerte contraste climático entre las planicies del Duero y Tajo y sus cíngulos montañosos; el acusado estiaje; la variable calidad de los pastos, etc. Además, el trazado de las vías pecuarias estuvo constreñido por factores históricos y fisiográfi-

Trab. Prehist., 76, N. ${ }^{\circ}$ 1, enero-junio 2019, pp. 67-83, ISSN: 0082-5638

https://doi.org/10.3989/tp.2019.12226 
cos, como el parcelario rural preexistente, los pasos de montaña y poblaciones, vados o puentes en los ríos. Habitualmente esas rutas se trazaban paralelas a cursos fluviales, por cuerdas a media altura y próximas a las cumbres y divisoras de aguas, como claras referencias visuales (Mangas 1992; Fairén et al. 2006: 59-60). La simulación de caminos óptimos mediante SIG para cotejar el trazado de vías pecuarias y corredores naturales transitables con el menor esfuerzo ha ofrecido resultados dispares: desde la divergencia espacial (Fairén et al. 2006: 64-67) a la estrecha coincidencia ${ }^{2}$ (MurrietaFlores 2010, 2012; Murrieta-Flores et al. 2011, 2014). Así pues, el diseño de las vías responde a múltiples factores y su trazado se consolidó por su recorrido consuetudinario, en ocasiones durante milenios.

Por último, nuestro objetivo es integrar en el análisis arqueológico esos cauces canalizadores del movimiento de gentes y animales y del traslado de cargas. Para ello adoptaremos planteamientos abiertos y flexibles, que no asuman actividades concretas (no verificables desde esta aproximación) ni asocien su uso a un modelo sociológico uniforme y estático; que en época moderna tuvieran un uso no implica que pueda aplicarse directamente a la Prehistoria (Esparza 1999: 98). Por eso abordamos aquí las vías pecuarias no como sucedáneos de la trashumancia moderna, sino como síntomas de lógicas culturales y prácticas sociales inveteradas, que pueden informar de estructuras subyacentes del paisaje (Fairén et al. 2006: 56).

Para evitar las deficiencias señaladas, resulta sugerente el concepto de conectividad ecológica: una propiedad del paisaje que informa sobre su capacidad para facilitar o entorpecer el movimiento de los herbívoros en su acceso a nichos discontinuos donde satisfacer sus necesidades (Taylor et al. 1993; Chen 2010). Hoy día las Humanidades conciben el espacio como una dimensión fluida, desigual y fragmentada en lugar de continua y regular. La arqueología del Mediterráneo ha empleado el concepto de conectividad del paisaje para rastrear la interacción entre localizaciones diseminadas: islas, establecimientos, etc. (Horden y Purcell 2000: 123-172; Souvatzi y Hadji 2014). En esa misma línea, aquí entenderemos la conectividad de los grupos estudiados como una propiedad histórica de su paisaje social, fruto de decisiones sobre su grado de participación o inhibición en el flujo de información, seres y materias circulantes (Mitrović 2016: 251-253). Este fenómeno también se beneficiaría del análisis de redes,

\footnotetext{
${ }^{2}$ Murrieta-Flores, P. 2007: Mobility, transhumance and prehistoric landscape. A GIS approach to the archaeological landscape of Almadén de la Plata in Andalucía, Spain. Trabajo de Máster inédito. University of Southampton. Gran Bretaña. Disponible en https://www.academia. edu/235419/Mobility_Transhumance_and_Prehistoric_Landscape._A GIS Approach to the Archaeological Landscape of A $\overline{\text { lmad }} \% \mathrm{C} 3 \% \overline{\mathrm{A}} \mathrm{n} \mathrm{n}$ de la Plata in Andaluc\%C3\%ADa Spain (consulta el 24/11/2017)
}

entendiendo los yacimientos como nodos conectados entre sí definiendo estructuras (Fairén et al. 2006: 56; Mitrović 2016: 115-122), pero eso excede nuestro propósito exploratorio.

Por último, combinaremos el concepto de conectividad con el modelo de interacción entre comunidades políticas paritarias (Renfrew 1986). Esa teoría permite un análisis social intermedio, entre las grandes dinámicas externas del comercio atlántico y mediterráneo y las culturas locales operando a escala local. El objetivo es abordar comunidades vecinas autónomas conectadas y funcionalmente equivalentes, sin presuponer un mayor papel de unas sobre otras, ni exigir un grado de sofisticación sociopolítica concreto, por lo que caben desde estados hasta jefaturas transigualitarias.

\section{MATERIAL Y MÉTODOS}

Hemos realizado un trabajo experimental, evaluando la supuesta relación entre los yacimientos del II milenio AC y las vías pecuarias. Recurrimos a los SIG porque permiten reducir la subjetividad inherente al acercamiento tradicional a la cuestión, meramente intuitivo y visual. No empleamos ningún programa de SIG para analizar la conectividad ecológica o para simular los corredores ${ }^{3}$ (Chen 2010) por la enorme dimensión del área de estudio y la desigual resolución de la cartografía disponible. Este ensayo se ha centrado en una zona del occidente de la península ibérica que cuenta con un importante número de yacimientos y con cartografía digital de las vías pecuarias. El espacio de trabajo es un transecto delimitado convencionalmente por las provincias españolas de León, Zamora, Salamanca, Cáceres, Badajoz y Huelva (Figs. 1A y 2). Esta franja comprende la vía natural de comunicación suroeste-noroeste, probablemente utilizada durante las Edades del Bronce y del Hierro (Ruiz-Gálvez 1998: 329-340, 1999; Galán y Ruiz-Gálvez 2001; Almagro-Gorbea 2008: 33), que terminará generando el trazado del Iter Ab Emerita Asturicam (Fig. 2). La infraestructura imperial romana coincide parcialmente con otros viales longitudinales en su misma dirección, como la Cañada Real Vizana o el Camino Mozárabe a Santiago (Mangas 1992). Todos ellos estuvieron cruzados por caminos trasversales con diversas direcciones y peor documentados (Fig. 2), pero básicos en el movimiento de gente y ganado prehistóricos (RuizGálvez 1998: 330-331).

La red viaria aquí comprendida se engloba bajo la denominación popular de Ruta de la Plata. Desde

\footnotetext{
3 Por ejemplo: http://corridordesign.org/designing_corridors/resources/gis_tools (consulta febrero de 2018).
} 


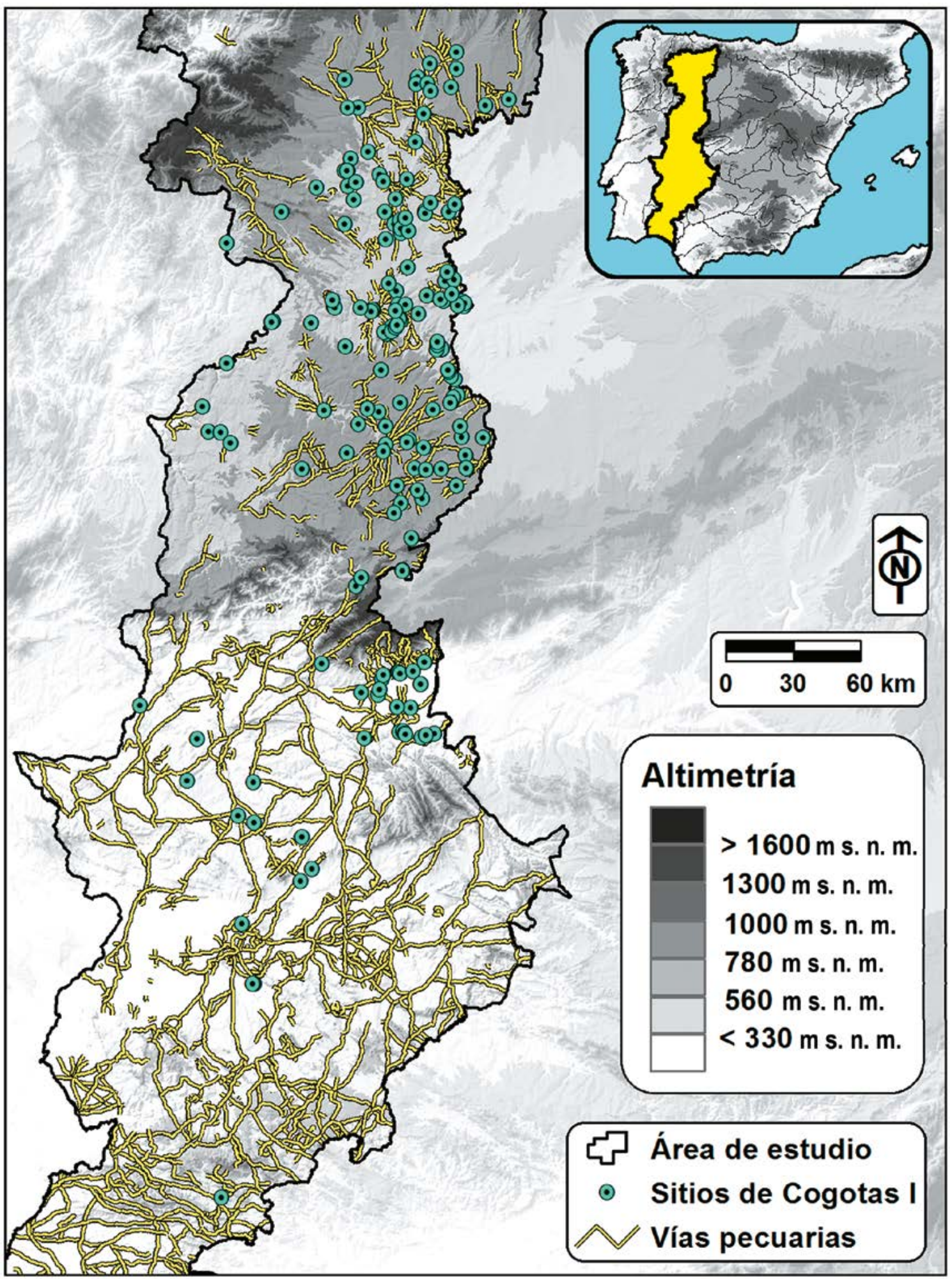

Fig. 2. Vías pecuarias y sitios de Cogotas I en la zona de estudio, sobre modelo digital de elevaciones (MDE) SRTM (Shuttle Radar Topography Mission) de la NASA (en color en la versión electrónica). 
el punto de vista histórico, e incluso legal, se compone de viales pecuarios jerarquizados por su anchura e importancia, desde la cañada (de $75 \mathrm{~m}$ de anchura) hasta otros caminos menores (cordel, vereda, colada, paso) (García Martín 1991; Mangas 1992: 12-14; Fairén et al. 2006: 57). La cartografía histórica, los mapas topográficos y la cartografía digital más reciente los recogen con bastante detalle (Figs. 1B y 2). Esta infraestructura, trazada y deslindada en su aspecto definitivo en época moderna, puede ser utilizada con fines comparativos (no reconstructivos) para investigar la movilidad prehistórica (cf. Fairén et al. 2006; Murrieta-Flores 2010, 2012; Murrieta-Flores et al. 2014). Las opciones para atravesar tales paisajes conectando puntos discontinuos fueron finitas. Así, aceptamos el supuesto razonable de que la caminería histórica responde a una secular acumulación de experiencia sobre el desplazamiento a pie por tales paisajes, con una dirección aproximada sur-norte, muy ajustado a las pendientes y al cruce de los cursos de agua, entre otros condicionantes. Ese conocimiento práctico de siglos fue sedimentando culturalmente las mejores rutas -que han permanecido- frente a otras opciones posibles.

En una zona de trabajo tan amplia, que comprende un altísimo número de yacimientos del II milenio AC, atribuibles a situaciones muy diversas, hemos considerado solo aquellos con material cerámico de Cogotas I, sin distinción de fases y tanto asentamientos como túmulos o monumentos (Fig. 2). Así, hemos elegido una muestra manejable de sitios con algún atributo compartido. La tabla de sitios resultante (Anexo en la versión electrónica) se ha elaborado a partir del Inventario Arqueológico de Castilla y León tras un escrutinio muy restrictivo, excluyendo los de atribución dudosa, añadiendo algunos nuevos y se ha reasignado la localización de todos ellos. Los sitios de Extremadura incluidos proceden de la bibliografía, y muy especialmente del trabajo de González Cordero (2015), y lo mismo sucede con el yacimiento de El Trastejón (Hurtado et al. 2011), el único con materiales de Cogotas I seguros en Huelva (Anexo en la versión electrónica).

Se ha utilizado un conjunto de capas de cartografía digital de la Infraestructura de Datos Espaciales de España (IDEE) y de sus equivalentes autonómicos, siendo especialmente importante la capa digital de Vías Pecuarias disponible en los geoportales del Ministerio de Agricultura, de la Junta de Castilla y León, la Junta de Extremadura y la Junta de Andalucía. Esta capa vectorial contiene tramos discontinuos (Fig. 2), debido a la desigual preservación de la red viaria por su destrucción y la usurpación privada de estos bienes demaniales (Mangas 1992; Ruiz Martín y García Sanz 1998; Fairén et al. 2006).
Hemos manejado el programa ArcGIS 10.4 de ESRI, con licencia de la Universidad de Salamanca. Se ha montado un proyecto para procesar las distintas capas digitales, siendo las fundamentales la de las vías pecuarias y la generada a partir de la tabla de yacimientos (Fig. 1B,C), así como otra capa de 176 puntos aleatorios generada con la opción Create Random Points (Fig. 3). Para el tratamiento estadístico de los datos se ha utilizado el programa XSTATS.

El método ha consistido en combinar las capas de yacimientos y de vías pecuarias, y también las de puntos aleatorios y vías pecuarias. Con la herramienta Proximity y la opción Near del programa ArcGIS se midió la distancia (lineal o euclidiana) mínima que hay entre cada uno de los sitios y cualquier tramo de vía pecuaria, y también entre cada uno de los puntos aleatorios y cualquiera de esos caminos. Con el comando Near Distance el programa incorpora los resultados a la tabla de atributos añadiendo una nueva columna. La anchura -física y legalmente fijada en el Medievo- de los caminos principales o "cañadas" (75 m) ha introducido cierta indefinición en las mediciones lineales. Sin embargo, esa restricción se ha compensado porque la holgura de las cañadas pudo probablemente comprender los titubeantes trazados de rutas seculares. Tras ensayarlas, rechazamos otras herramientas complementarias empleadas en trabajos similares, como los cálculos de cuencas visuales y la exposición visual entre vías y yacimientos (Criado y Vaquero 1993: 215-217; MurrietaFlores et al. 2014: 83-86), ya que la mayoría de los sitios analizados son de llanura, sin apenas visión de los caminos. Además, la baja resolución de la cartografía digital disponible para tan amplísima zona de trabajo ofrece recreaciones poco matizadas.

Los datos obtenidos permiten apoyarse en la estadística inferencial para comparar los valores de las mediciones de distancias entre ambos grupos de puntos -el de los yacimientos cogotenses y el de los puntos aleatorios- respecto a las vías pecuarias. Se puede formular la hipótesis de partida de que ambas 'poblaciones' (en el sentido estadístico del término) son idénticas. Esta sería la hipótesis nula $\left(\mathrm{H}_{0}\right)$, que se ha sometido a contraste mediante la prueba de Kruskal-Wallis, adecuada para la naturaleza no paramétrica de los datos. De aceptar esa $\mathrm{H}_{0}$, habríamos de concluir que la relación de los yacimientos estudiados con las vías pecuarias es análoga a la de los puntos aleatorios. El rechazo de la $\mathrm{H}_{0}$ llevaría a aceptar que la distancia entre sitios y caminos no parece deberse al azar, y por tanto, hay motivos razonables para sospechar que su proximidad pudiera ser resultado de una decisión cultural. En cualquier caso, el recurso a este test no paramétrico no confirma nada, ni es un fin en sí mismo; simplemente informa de si merece la pena continuar afinando la cuestión (Eve y Crema 2014: 267). 


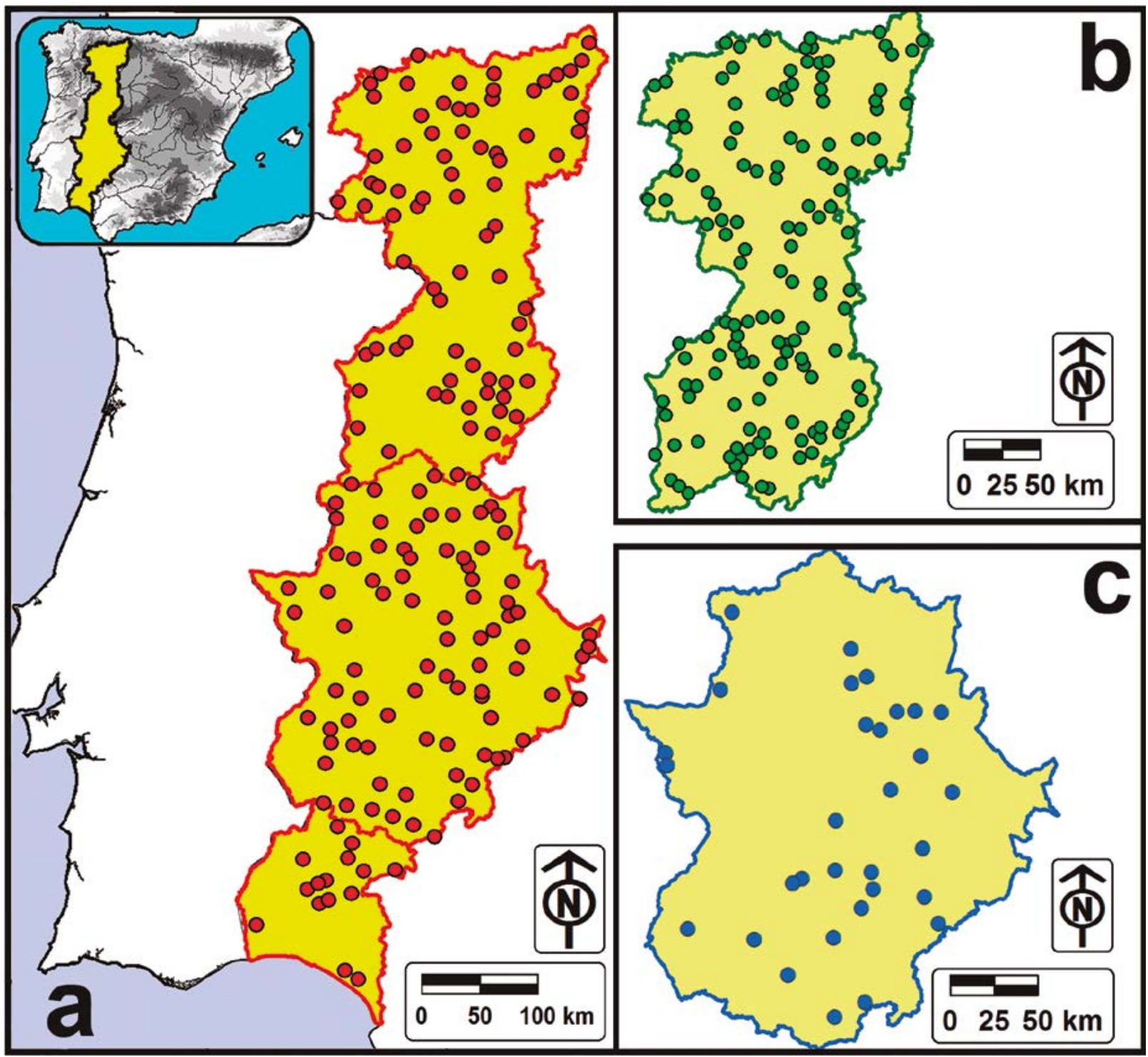

Fig. 3. Puntos aleatorios generados: A. sobre el área de estudio completa; B. en el sector norte (Castilla y León); C. en el sector sur (Extremadura) (en color en la versión electrónica).

\section{DISCUSIÓN}

Para pronunciarnos sobre la hipótesis nula, el test de Kruskal-Wallis ha procurado los siguientes resultados (Tab. 1): al tratar todos los sitios de la zona de trabajo en conjunto, el valor observado $(\mathrm{K}=7.036)$ es superior al valor crítico $(3,841)$ y su probabilidad $(\mathrm{p}$ $=0,008)$ es menor que el nivel de significación $(\alpha=$ 0,05 ), por lo que se rechaza la $\mathrm{H}_{0}$. Los yacimientos y los puntos aleatorios no proceden de una misma población estadística; la relación entre ambos es genuina, no responde al azar. Esta garantía inicial indica que conviene seguir ahondando en este planteamiento.

Antes de seguir, y a la vista del mapa de dispersión de los yacimientos considerados (Fig. 2), parece justificado explorar la posibilidad de que haya diferencias regionales entre dos sectores separados por el Sistema Central: el de la parte más occidental de la submeseta norte (que comprende 141 sitios) y el de Extremadura (con 34 casos). Se ha excluido El Trastejón (Huelva) porque su marginalidad podría distorsionar los resultados. Las mediciones de esos mismos subconjuntos de datos se han cotejado con igual número de nuevos 


\begin{tabular}{|l|c|c|c|c|c|}
\hline \multicolumn{1}{|c|}{ Muestra de sitios } & Valor K & $\begin{array}{c}\text { Valor crítico } \\
(\mathbf{1} \text { gl) }\end{array}$ & Valor p & Valor $\boldsymbol{\alpha}$ & Interpretación \\
\hline Área de estudio completa & 7.036 & 3,841 & 0,008 & 0,05 & Diferencia significativa. Se rechaza $\mathrm{H}_{0}$ \\
\hline Subsector de Castilla y León & 32.399 & 3,841 & $<0,0001$ & 0,05 & Diferencia significativa. Se rechaza $\mathrm{H}_{0}$ \\
\hline Subsector de Extremadura & 2,427 & 3,841 & 0,119 & 0,05 & Diferencia no significativa. Se acepta $\mathrm{H}_{0}$ \\
\hline
\end{tabular}

Tab. 1. Resultados del test de Kruskal-Wallis para tres grupos de sitios de Cogotas I en la zona de estudio y su lectura con un $95 \%$ de probabilidad $(\mathrm{gl}=$ grado de libertad).

puntos aleatorios (Fig. 3): cálculo de las distancias de unos y otros a la caminería histórica con la función Near y evaluación probabilística con la prueba de Kruskal-Wallis.

En primer lugar, se presentarán los resultados obtenidos para el sector de la submeseta norte (Tab. 1). En este caso, el valor observado $(\mathrm{K}=32,399)$ es superior al valor crítico $(3,841)$, y su probabilidad $(\mathrm{p}<0,0001)$ es menor que el nivel de significación $(\alpha=0,05)$, por lo que también debe rechazarse la hipótesis nula y aceptar la hipótesis alternativa. En cambio, al analizar por separado el sector de Extremadura (Tab. 1) el valor observado $(K=2,427)$ es inferior al valor crítico $(3,841)$, y su probabilidad $(p=0,119)$ es mayor que el nivel de significación $(\alpha=0,05)$, por lo que en este caso no se puede rechazar la $\mathrm{H}_{0}$. Así pues, en ese tramo concreto parece que la proximidad entre los yacimientos considerados y la red caminera pudiera ser aleatoria.

Si nos atenemos a los resultados de las pruebas estadísticas, que ofrecen un resultado inmediato de este trabajo, parece que en la zona de las provincias occidentales de España -y especialmente en León, Zamora y Salamanca-, entre los factores de localización de los yacimientos de Cogotas I podría estar la proximidad a unas vías de tránsito que parecen haber prefigurado las vías pecuarias de época moderna. El resultado negativo del sector extremeño, indistinguible del puro azar (Tab. 1), no sorprende tanto si consideramos que allí el número de yacimientos conocidos es mucho menor ${ }^{4}$. De ampliarse las prospecciones la imagen sería diferente, como sugieren los trabajos en el Campo Arañuelo (Cáceres) (González Cordero 2015, o el material de superficie cogotense hallado en la Sierra de Tiros (Badajoz) (Pavón et al. 2018: Figs. 9-10 y 12).

\footnotetext{
${ }^{4}$ Para evaluar la posible existencia de diferencias en las distancias yacimientos-vías pecuarias entre el sector norte y el sector sur, se llevó a cabo un ANOVA, que no apreció diferencias estadísticamente significativas entre ellos $[\mathrm{F}(1,173)=2.95, \mathrm{p}=.08]$. En cambio, la prueba $t$ para muestras independientes sí señala discrepancias estadísticamente significativas $[\mathrm{t}(80.1)=2.27, \mathrm{p}=.26]$. Esta disparidad se debe a lo provisiona de los datos disponibles en ambos sectores, cuyo muy distinto conocimiento apenas permite compararlos.
}

El tratamiento estadístico de las magnitudes obtenidas permite también reflexiones de índole exploratoria. La media de las distancias entre yacimientos y vías $(2.502,92 \mathrm{~m})$ carece de interés por su fuerte desviación típica $(2.613,81)$, debida a la heterogeneidad y dispersión de las mediciones (Fig. 4A). En cambio, la representación gráfica de las distancias (Fig. 4B) permite advertir la importante cantidad de yacimientos bastante próximos a algún camino tradicional: nada menos que 48 sitios -el $27,3 \%$ del total- están a menos de $500 \mathrm{~m}$, y otros 16 (el 9,1\%) se localizan entre 500 y $1.000 \mathrm{~m}$ de algún ramal caminero. En otras palabras, el $36,4 \%$ de los yacimientos se localiza bastante próximo $(<1 \mathrm{~km})$ a algún tramo de vía pecuaria. Por contra, 79 sitios (el 44,9\%) están más allá de los $2 \mathrm{~km}$ de distancia (Fig. 4B).

Los gráficos de los dos subsectores individualizados dentro del área de trabajo también son relevantes. La figura $4 \mathrm{C}$, relativa a las provincias de Castilla y León, muestra nuevamente la importancia de los yacimientos muy próximos $(<500 \mathrm{~m})$ a cualquier tramo de vía pecuaria $(26,2 \%)$, a los que se se podrían añadir los ubicados entre 500 y $1.000 \mathrm{~m}$, para alcanzar un total de 36,2\%. Ello corrobora la impresión general: un tercio de los sitios podrían justificarse, entre otros factores de emplazamiento, por la proximidad a las vías en cuestión. Respecto a la zona de Extremadura, aunque el test de Kruskal-Wallis no permite rechazar el carácter fortuito de la relación (Tab. 1), lo cierto es que el diagrama de barras (Fig. 4D) indica también la gran importancia de los yacimientos muy próximos a vías $(32,4 \%)$. Eso sí, el porcentaje de los yacimientos a menos de $1 \mathrm{~km}$ de distancia $(38,3 \%)$ es el mismo que el de los yacimientos más alejados $(>2 \mathrm{~km})$.

Este ensayo, de carácter no reconstructivo sino experimental, se encaminaba a verificar o rechazar la hipótesis de trabajo que relaciona los sitios de Cogotas I en la zona estudiada con las vías pecuarias, como un parámetro que puede informar indirectamente de su conectividad. Como se ha visto, habría que aceptar la validez de la relación espacial entre sitios y vías, ya que una parte -no pequeña, en torno a un tercio del total- de los yacimientos analizados cumpliría la condición de situarse a menos de $1 \mathrm{~km}$ de algún ramal de 

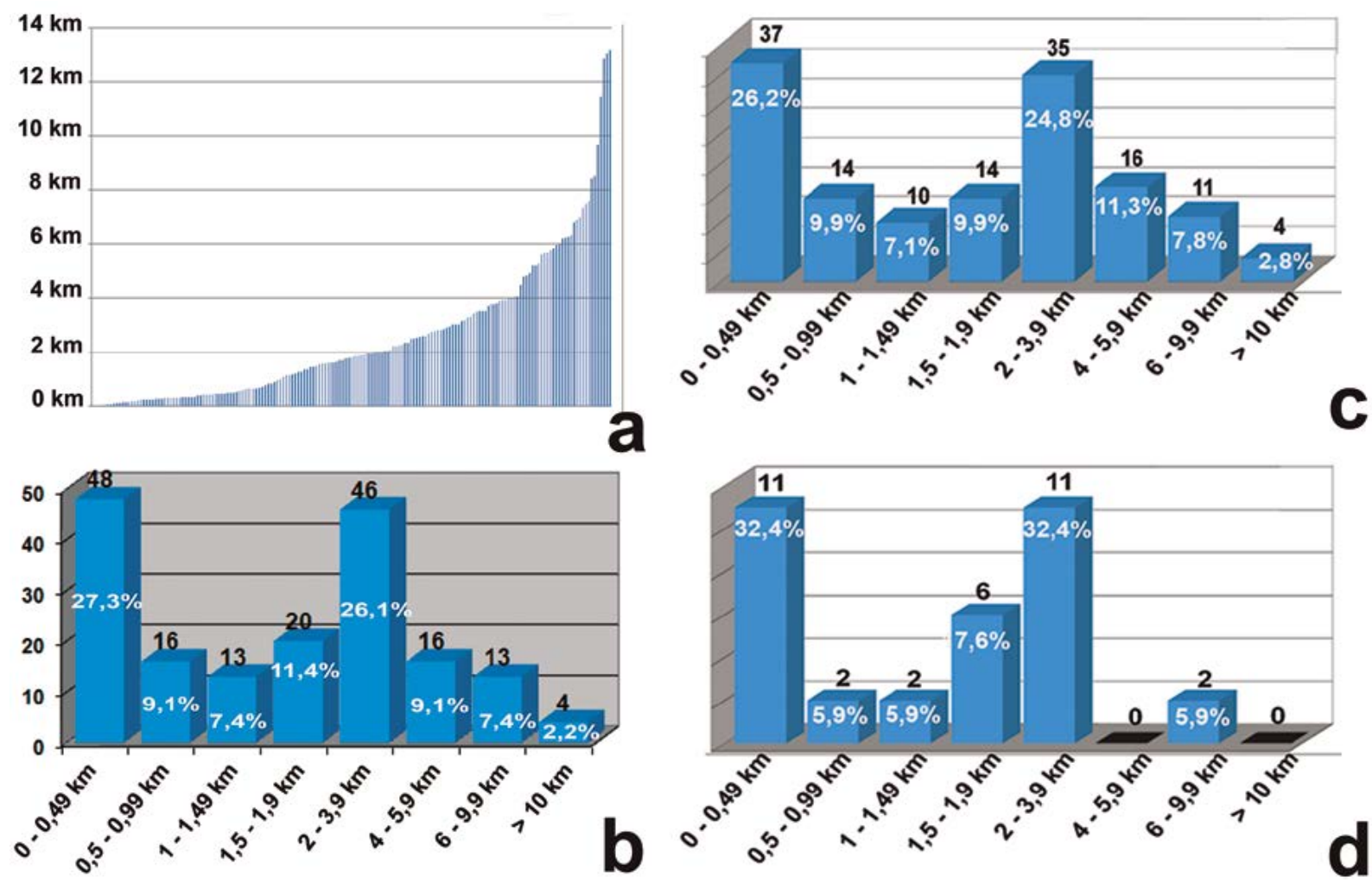

Fig. 4. Distancias entre los yacimientos de Cogotas I y las vías pecuarias a la izquierda en la zona de trabajo: A. desde cada sitio. B. agrupadas por categorías y a la derecha por sectores: C. Norte (Castilla y León). D. Sur (Extremadura) (en color en la versión electrónica).

la caminería tradicional. Eso sí, como contrapeso de esa afirmación, no debe olvidarse la elevada proporción que suponen los yacimientos más alejados de las cañadas ( $>2 \mathrm{~km}$ de distancia), que alcanzan cifras en torno al $45 \%$, tanto en toda la zona de estudio como en los subsectores de la submeseta norte y Extremadura (Fig. 5).

Más allá del resultado del experimento, si se acerca el foco a los yacimientos mejor conectados, a menos de $500 \mathrm{~m}$ de algún tramo de vía pecuaria, podrían hacerse también algunas consideraciones. La mayoría de ellos viene a coincidir con el recorrido principal, mejor consolidado y de mayor capacidad de tránsito, de las cañadas reales conocidas como Vía de la Plata (Fig. 5): desde los leoneses (en Anexo en la versión electrónica, n. $\left.{ }^{\circ} 4,5,10,12,15,34\right)$; los zamoranos (en Anexo, n. ${ }^{\circ}$ 23, 24, 26, 30, 55, 58, 61, 71, 73, 85), que continúan hacia el sur con los salmantinos (en Anexo, n. $\left.{ }^{\circ} 108,111,112\right)$, hasta llegar, a través de la zona del puerto de Béjar (en Anexo, n. ${ }^{\circ} 138,140$ ) -algo menos cercanos pero en posiciones de claro dominio visual-, a los extremeños de Maltravieso, El Carrascalejo y Alange (en Anexo, n. ${ }^{\circ} 168,173,174$ ), para concluir en El Torrejón (Zufre), ya en la serranía onubense (en Anexo, n. ${ }^{\circ}$ 176). Es decir, que el eje de todos los trazados viales posibles según distintos factores, en cuya cercanía los sitios del II milenio AC se localizaron más coincide con los sucesivos caminos históricos, que fosilizan así unos usos inveterados.

Otra observación no desdeñable: algunos puntos que hoy parecen un tanto excéntricos en el mapa de yacimientos del II milenio AC pudieran responder también a la inmediatez de otros ramales de tránsito menores, como veredas y coladas (Fig. 5). Tal es el caso, por ejemplo, del castro de Muelas del Pan o de Ledesma (en Anexo, n. ${ }^{\circ}$ 46, 104) y, sobre todo, de los detectados en el denso foco cacereño del valle del Tiétar-La Vera (en Anexo, n. ${ }^{\circ}$ 142-162).

Pese a su desigual reparto por una región tan extensa, en los sitios considerados se constatan algunas de las pautas de comportamiento compartido que definen Cogotas I: la presencia de alfarería con las características decoraciones, la proliferación de estructuras subterráneas, el débil rastro de las viviendas, ocasionales enterramientos en hoyos, etc. (FernándezPosse 1998; Delibes y Romero 2011; Blasco 2012). 


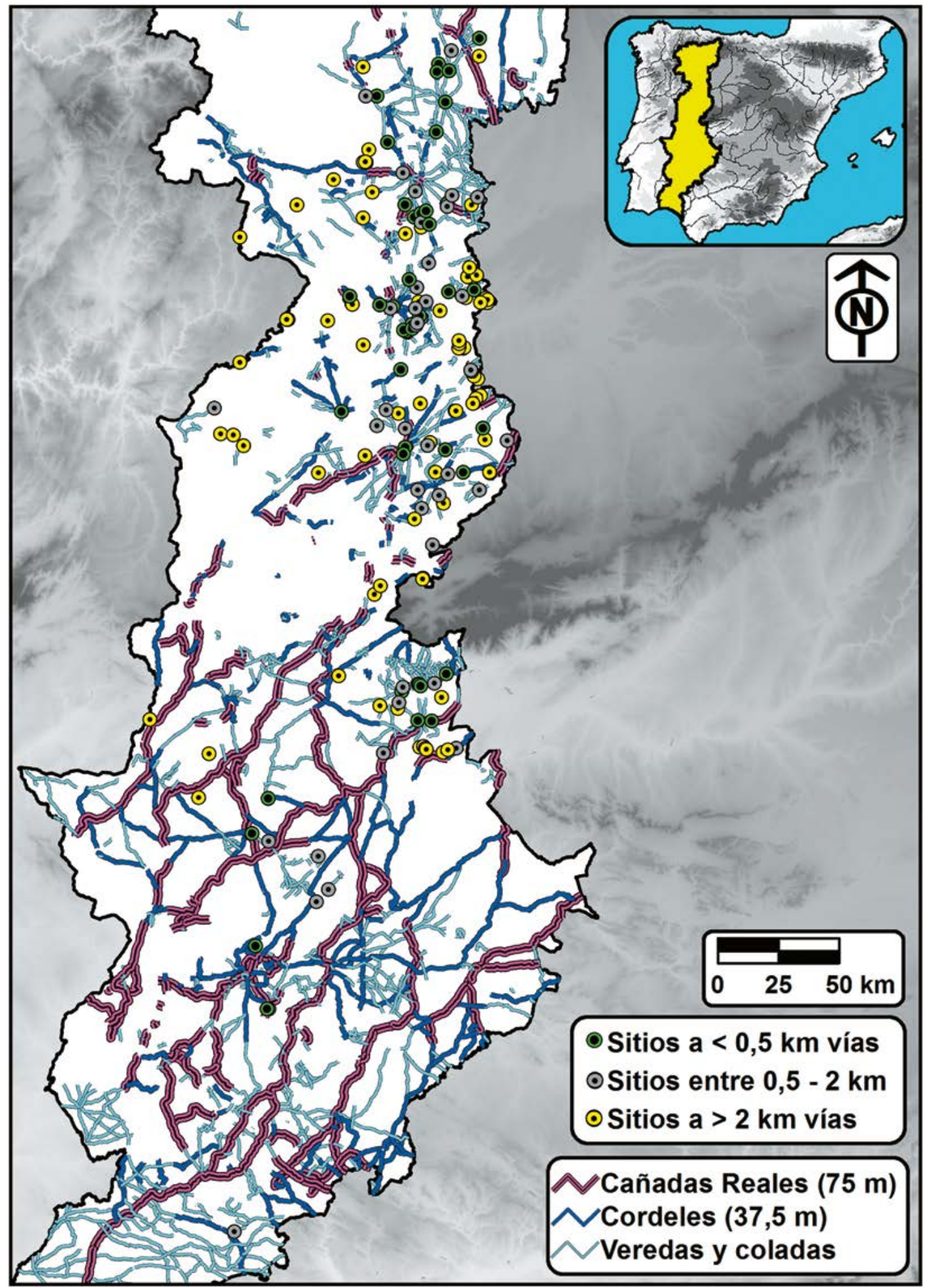

Fig. 5. Sitios de Cogotas I (clasificados según su distancia a alguna vía pecuaria), y caminería histórica (según su importancia) en el área de trabajo sobre modelo digital de elevaciones (MDE) SRTM (Shuttle Radar Topography Mission) de la NASA (en color en la versión electrónica). 
Contamos además con pruebas directas del intercambio de materias primas (López-Plaza et al. 2018), así como de la circulación de algunas mujeres a través del Sistema Central, como han mostrado recientes análisis de isótopos estables (Díaz-del-Río et al. 2017), probablemente debido a intercambios exogámicos (Abarquero 2012: 95-96). Así pues, hay margen para caracterizar la interacción y el intercambio sin invocar esa manida categoría de los objetos de prestigio. Pero los yacimientos estudiados no responden a una única tipología, ni sus criterios de localización fueron uniformes: predominan los lugares de llanura (Rodríguez Díaz y Enríquez 2001; Abarquero 2005; González Cordero 2015), pero la ruta está jalonada por enclaves conspicuos, como el salmantino inédito de Peña Blanca (en Anexo, n. ${ }^{\circ}$ 125); el cacereño Castillo de Alange (en Anexo, n. ${ }^{\circ}$ 174) (Rodríguez Díaz y Enríquez 2001); o el onubense de El Trastejón (en Anexo, n. ${ }^{\circ}$ 176) (Hurtado Pérez et al. 2011). Así pues, la proximidad a vías de tránsito fue uno más entre los factores barajados para establecerse. Otros criterios también considerados parecen haber sido la orientación e insolación, el tipo de suelo y los recursos accesibles, la disponibilidad de agua y, sólo en algunos casos, la visibilidad desde esos emplazamientos (Pavón et al. 2018: 53-57). Su localización probablemente respondió a una decisión grupal juiciosa y equilibrada antes que a los intereses de unos pocos. Trabajar desde tales pautas del poblamiento -resultado de estrategias consensuadas y 'democráticas'- contribuye pues a elaborar lecturas alternativas al tradicional énfasis en las élites, dando voz a otros agentes sociales también participantes (Delgado 2013: 322-327).

La inmediatez de los yacimientos arqueológicos a las rutas pecuarias no informa de ninguna actividad económica concreta. Aquí defendemos que esa variable probablemente dependió de la importancia otorgada a facilitar la conectividad de tales lugares. Desde tal postura, el análisis arqueológico permite esbozar las tendencias diacrónicas de la conectividad del poblamiento junto al trayecto suroeste-noroeste aquí analizado (Fig. 2). Así, durante el III milenio AC esa ruta funcionó ya como eje facilitador de contactos, pero las verdaderas arterias del occidente peninsular fueron los principales ríos que lo cruzan en sentido este-oeste: Guadiana, Tajo y Duero (Celestino 2001; Galán y Ruiz-Gálvez 2001; Rodríguez Díaz y Enríquez 2001), especialmente durante la etapa campaniforme (Liesau 2016). En el II milenio AC la interacción interregional se dinamizó a una nueva escala, canalizada por las rutas marítimas y fluviales y ahora especialmente por las terrestres (Ruiz-Gálvez 1998: 101-107; 2013: 272286; Álvarez-Sanchís 1999; Galán y Ruiz-Gálvez 2001; Celestino 2001; Almagro-Gorbea 2008; ÁlvarezSanchís et al. 2016). Es entonces, durante el Bronce
Tardío y Final, cuando ensayos con SIG como el efectuado en Almadén de la Plata (Sevilla) muestran la mayor proximidad de los asentamientos a los corredores terrestres naturales. Ello se ha interpretado como un desinterés en la producción agraria, frente al énfasis en el intercambio de productos no subsistenciales, como los metales (Murrieta-Flores 2012: 114-117; Murrieta-Flores et al. 2014: 81). Esa observación y la proliferación de enclaves con ocupaciones breves -posibles cuevas-redil y campamentos estacionales- han llevado a sugerir cierta especialización ganadera en unos paisajes adehesados de tal 'vocación' (Ruiz-Gálvez 1998: 235; Murrieta-Flores et al. 2014: 81). Pero, como venimos defendiendo, la cercanía de hitos, monumentos o instalaciones prehistóricas a las vías pecuarias y la huella efímera del hábitat no indican necesariamente unas estrategias ganaderas especializadas. Tampoco son indicadores adecuados para estimar la importancia relativa del pastoreo entre grupos que pudieron integrarlo con otras prácticas de subsistencia (Pavón et al. 2018: 57). De hecho, la diversificación agroforestal (Díaz-del-Río 1995, 2001; FernándezPosse 1998) tuvo muy largo recorrido en la Prehistoria del occidente ibérico, y el sistema de dehesa (RuizGálvez 1993, 1998: 118-120; Murrieta-Flores 2014: 198-200) se basa en la combinación de ganadería y agricultura.

Una línea de evidencia más consistente para hablar de especialización estacional sería la proximidad de sitios provisionales a rutas de trasterminancia local valle-montaña (Galaty y Johnson 1990; Mlekuž 2005). En cualquier caso, el peso concreto de la ganadería y la posible -pero poco probable- especialización pastoril deben caracterizarse con rigor, desligando su análisis de estereotipos atemporales, supuestamente impuestos por las condiciones naturales (Horden y Purcell 2000: 467-487). En este sentido, calificar la importancia relativa de la ganadería y reconocer la trashumancia o la trasterminancia prehistóricas no son tarea sencilla. El movimiento regular de pastores con su grey ha sido discutido en Arqueología con muy desiguales argumentos (Barker 1985; Walsh 2014). En Iberia, el traslado del ganado a pastos estivales está bien constatado desde el Neolítico antiguo (Badal 1999; RojoGuerra et al. 2013; 2014) y ha perdurado hasta tiempos subactuales (Fernández Mier y Tente 2018). Entre las pruebas indirectas empleadas en su diagnóstico, la arqueobotánica ofrece valiosa información, al perfilar el impacto zooantrópico de tales ciclos pastoriles en entornos montañosos, a partir de efectos como el clareo del bosque por rozas con fuego y ramoneo, o la frecuencia de hongos coprófilos (López-Sáez et al. 2018). Combinando la micromorfología, los fitolitos y la carpología (Lancelotti et al. 2014) se han reconocido agostaderos de media y alta montaña -majadas, cue-

Trab. Prehist., 76, N. ${ }^{\circ}$ 1, enero-junio 2019, pp. 67-83, ISSN: 0082-5638

https://doi.org/10.3989/tp.2019.12226 
vas-redil-, ocupados repetidamente para aprovechar los pastos de veranada (Ruiz-Gálvez 1998: 329-340; Lozny 2013). También las colecciones osteológicas del ganado permiten diagnosticar pautas complementarias de sacrificio entre la montaña y el llano (Arnold y Greenfield 2006); mediante elementos traza metálicos que indiquen regiones de pasto específicas (Logemann et al. 1995); o a partir de la huella isotópica adquirida por su dieta (Balasse 2014; Makarewicz y Sealy 2015). En suma, cualquier estimación robusta sobre las estrategias pastoriles y su estacionalidad precisa cotejar líneas de inferencia independientes.

Respecto a lo aprendido con este experimento sobre la organización sociopolítica en la zona de estudio, es innegable que un único modelo sociológico difícilmente podría cubrir la rica casuística abordada. Las gentes a lo largo de los casi $700 \mathrm{~km}$ lineales del itinerario principal considerado mantuvieron paisajes sociales diversos, contando con recursos muy desigualmente repartidos y bajo coyunturas cambiantes. No nos parece plausible que el recorrido sur-norte aquí estudiado hubiera articulado relaciones de dependencia interregional entre un centro difuso en la baja Andalucía y una extensa, desagregada y mal comunicada periferia interior (Ruiz-Gálvez 1993; Celestino 2001; Rodríguez Díaz y Enríquez 2001). Esos grandes relatos, con jerarcas y poderosos factores externos, no encuentran acomodo empírico al bajar al detalle (Gilman 1993), ni en experimentos como el aquí propuesto. Pensar en términos de comunidades políticas paritarias (Renfrew 1986), podría ayudar a comprender mejor esas dinámicas históricas (Esparza 1999: 109). Aunque la formulación original de la interacción entre grupos autónomos y equivalentes se centró en pequeños estados secundarios y jefaturas complejas (Renfrew 1986), esa teoría es suficientemente flexible para admitir sociedades con fuentes de poder y grados de integración política diversos. Además evita explícitamente subordinar las dinámicas endógenas a vectores externos (Renfrew 1986: 2-8). La clave de su análisis radica en la interacción a escala intermedia -entre las comunidades locales y el sistema macrorregional-, centrada en entidades vecinas interconectadas y transformándose bajo factores compartidos. En el II milenio $\mathrm{AC}$, a lo largo de la franja estudiada encontramos tradiciones culturales y formas de organización social heterogéneas.

El modelo de Renfrew (1986) permite apreciar mejor la gradación sur-norte de las expresiones materiales elitistas de entonces, como las estelas o la orfebrería (Díaz-Guardamino 2010): pertenecen a comunidades políticamente variadas, transformándose a muy distinto ritmo y en sentidos no coincidentes, pero interconectadas. En el sector centro-sur hay muestras esporádicas de acumulación de riqueza y ocasionalmente pudieron funcionar organizaciones políticas comarcales (García Sanjuán 1999; Rodríguez Díaz et al. 2015), pero antes del I milenio AC sus formas de poder apuntan a pequeñas jefaturas territoriales efímeras. Al norte del río Tajo se han reconocido organizaciones transigualitarias y tribales de tipo big man, facilitadas por el control del trabajo agrario y plasmadas en el consumo ostentoso de productos importados (Vilaça 1995; Armada 2013). En el ámbito de Cogotas I los indicios comparables de riqueza escasean - una posible familia de cierto rango enterrada en San Román de Hornija (Valladolid), unas pocas preseas áureas- (Abarquero 2005; Delibes y Romero 1992, 2011). Tan costosas exhibiciones de economía política no desentonan con lo esperable entre sociedades agrarias igualitaristas, cuya solidaridad parentelar no se quebró y que carecieron de base material para garantizar su reproducción (Gilman 1995; Díaz-del-Río 1995, 2001). A ello se añadió la probable resistencia activa y la demostrada resiliencia del cuerpo social contra tales conatos de división (Harrison 1994: 80-85; Fernández-Posse 1998: 120-122). Algunos de esos grupos optaron por primar su conectividad, pero su rastro material ofrece una profunda impresión de humildad e isonomía, que no hay que confundir con subdesarrollo o rudeza (Gilman 1993: 109). Así, en las tierras del Duero occidental y el Tajo medio, varias comunidades dispersas habrían decidido situarse junto a rutas de paso, para facilitar el mantenimiento de vínculos con jerarquías efímeras como las del centro-norte de la fachada atlántica peninsular (Vilaça 1995; Armada 2013). De aquella decisión no cabe deducir consecuencias directas sobre su organización social. Resistir activamente contra el surgimiento de jerarquías y participar de la circulación de conocimientos, personas y bienes pueden ser decisiones culturales compatibles. Hacia mediados del I milenio AC todas esas trayectorias políticas convergieron en sociedades heterárquicas o germánicas (Gilman 1995) comparables. La ruta surnorte estudiada tuvo entonces un papel fundamental en la recepción de gentes e innovaciones que contribuyeron a las transformaciones de la Edad del Hierro (Ruiz-Gálvez 1998: 230; Almagro-Gorbea 2008; Rodríguez Díaz et al. 2015).

\section{CONCLUSIONES}

Este trabajo ha tratado de mostrar las ventajas de recurrir a un concepto transversal como el de conectividad. Esa propiedad del paisaje permite trascender el análisis cultural estándar, parcelado en las unidades de observación habituales, coherentes y bien demarcadas (culturas, etapas, regiones) y atender mejor a la fluidez y discontinuidad del paisaje como palimpsesto 
y como mosaico. La conectividad es una variable relativa, pero medible de forma indirecta mediante herramientas de SIG de amplio uso. Como experimento, el trabajo ha pretendido ser sólo un primer paso, imperfecto e inacabado, para efectuar comparaciones similares ensayando otros ámbitos de estudio, con muestras alternativas y explotando mejor la perspectiva diacrónica. Nuestro enfoque no ha asumido una correlación necesaria entre mayores valores de conectividad -medible con la estrategia aquí ensayada o con otras posibles- y mayor volumen de mercancías, personas o ganados encauzados. De hecho, Cogotas I se caracterizó como fenómeno social por su fragmentación, resiliencia y aislacionismo en la mayor parte de su vigencia y ámbito geográfico (Fernández-Posse 1998). Además, los contextos de hallazgo de los objetos trasladados por rutas como la estudiada solo informan del final de sus ciclos de uso o biografías, de su desactivación social -abandono, destrucción, ocultación, etc.-, y no necesariamente de su consumo o destino. Una vez más se constata que el funcionamiento social es difícilmente reducible a su huella arqueológica, sesgada y muy parcial.

Para continuar avanzando hacia la resolución de los problemas aquí planteados, sería ineludible el examen detallado de los materiales, especialmente las cerámicas decoradas, que comparecen en esos yacimientos más estrechamente relacionados con las vías pecuarias. No es una empresa fácil, por la gran cantidad de material disponible, procedente de prospecciones de superficie. Pero ya se ha señalado (SánchezPolo 2011) cómo ciertos patrones decorativos con la técnica del puntillado se reconocen en sitios junto a ese alineamiento fundamental norte-sur, desde El Juncal de Villaralbo (Zamora) al Castillo de Alange (Badajoz) (en Anexo en la versión electrónica, n. ${ }^{\circ} 71$ y 174) o desde el valle medio del río Esla hasta la zamorana Tierra del Vino. En otro trabajo muy diferente (López-Plaza et al. 2018) se ha insistido en esas conexiones deducibles de las cerámicas para justificar el tráfico de otros materiales, como la materia prima de los molinos de vaivén, prescindiendo del cliché del pastor nómada (Díaz-del-Río 2001: 82). Estamos ante un problema que no se limita estrictamente a la cuestión del desplazamiento de ganados, sino que remite más bien a la interrelación entre grupos con desigual organización política. Ahora se están efectuando también análisis de isótopos estables de los restos humanos de la submeseta norte, otra posible vía para identificar desplazamientos humanos, tal vez relacionados con la caminería aquí tratada.

Los resultados alcanzados invitan a proseguir el ensayo aquí realizado, mejorando las condiciones del experimento: si se pudiera disponer del contorno aproximado de todos los yacimientos $-\mathrm{O}$ al menos de aque- llos muy próximos a las cañadas- y de una cartografía digital de mayor precisión -ahora disponible para la provincia de Valladolid-, se podría evaluar la hipótesis utilizando, en vez de las distancias lineales, los tiempos de marcha a pie. La relevancia del problema de fondo, esto es, la identificación de redes sociales que facilitaron el intercambio de bienes, conocimientos y personas, bien lo merecería.

\section{AGRADECIMIENTOS}

La Junta de Castilla y León facilitó el acceso al inventario arqueológico regional y el Dr. Antonio González Cordero el texto de su contribución al Coloquio Histórico-Cultural del Campo Arañuelo, una fuente esencial para Extremadura. El Ministerio de Agricultura y Pesca, Alimentación y Medio Ambiente nos proporcionó la capa vectorial de "cañadas". Otra cartografía digital consultada está disponible en la Infraestructura de Datos Espaciales de España (IDEE) y en los geoportales de las comunidades autónomas de Castilla y León (IDECyL), Extremadura (IDEEX) y Andalucía (IDEA). Dos revisores anónimos y los editores de la revista ayudaron a mejorar el trabajo.

\section{BIBLIOGRAFÍA}

Abarquero Moras, F. J. 2005: Cogotas I. La difusión de un tipo cerámico durante la Edad del Bronce. Junta de Castilla y León. Valladolid.

Abarquero Moras, F. J. 2012: "Cogotas I más allá del territorio nuclear. Viajes, banquetes y regalos en la Edad del Bronce peninsular". En J. A. Rodríguez Marcos y J. Fernández Manzano (eds.): Cogotas I, una cultura de la Edad del Bronce en la Península Ibérica. Universidad de Valladolid. Valladolid: 59-110.

Abarquero Moras, F. J.; Delibes de Castro, G.; Fernández Rodríguez C.; González Fernández, M. L. y López Sáez, J. A. 2009: "Una ojeada a la hipótesis de la hipermovilidad de los "pastores de excisión y boquique' a la luz de los documentos de El Pelambre". En M. L. González Fernández (ed.): El Pelambre, Villaornate, León. El horizonte Cogotas I de la Edad del Bronce y el periodo tardoantiguo en el Valle medio del Esla. Tragsa. Madrid: 291-302.

Almagro-Gorbea, M. 1977: El Bronce Final y el Periodo Orientalizante en Extremadura. Bibliotheca Praehistorica Hispana XIV, CSIC. Madrid.

Almagro-Gorbea, M. 2008: "Los caminos occidentales de la Península Ibérica antes de la Vía de la Plata”. En A. M. Montalvo Frías (ed.): La Vía de la Plata: una calzada y mil caminos. Museo Nacional de Arte Romano. Mérida: 32-40.

Álvarez-Sanchís, J. R. 1999: Los Vettones. Real Academia de la Historia. Madrid.

Álvarez-Sanchís, J. R.; Lorrio Alvarado, A. J. y Ruiz Zapatero, G. 2016: "Los primeros elementos de hierro en Iberia". Anejos a Cuadernos de Prehistoria y Arqueología de la Universidad Autónoma de Madrid 2: $149-165$.

Armada, X. L. 2013: "Big men showing off: the ideology and practice of social inequality in the Atlantic Late Bronze Age of Iberia". En M. Cruz Berrocal, L. García Sanjuán y A. Gilman (eds.): The Prehistory of Iberia. Debating Early Social Stratification and the State. Routledge. New York: 267-291. 
Arnold, E. R. y Greenfield H. J. 2006: The origins of transhumant pastoralism in temperate Southeastern Europe. British Archaeological Reports, International Series 1538, BAR Publishing. Oxford.

Badal, E. 1999: "El potencial pecuario de la vegetación mediterránea: las cuevas redil”. En II Congrés del Neolitic a la Península Ibérica (València 1999). Sagvntvm-Plav, Extra 2: 69-75.

Balasse, M. 2014. "Isotopic studies of husbandry". En C. Smith (ed.): Encyclopedia of Global Archaeology. Springer. New York: 41204128.

Barker, G. 1985: Prehistoric farming in Europe. Cambridge University Press. Cambridge.

Blasco Bosqued, M. ${ }^{a}$ C. 1993: El Bronce Final. Síntesis. Madrid

Blasco Bosqued, M. ${ }^{\text {a }}$ C. 2012: "Cogotas I en la Meseta Española". En J. A. Rodríguez Marcos y J. Fernández Manzano (eds.): Cogotas I, una cultura de la Edad del Bronce en la Península Ibérica. Universidad de Valladolid. Valladolid: 187-218.

Cabo Alonso, A. 1994a: "Medio natural y trashumancia en la España peninsular". En G. Anes y A. García Sanz (eds.): La Mesta. Trashumancia y vida pastoril. Junta de Castilla y León. Valladolid: 23-45.

Cabo Alonso, A. 1994b: "La Iberia nómada. Medio físico y trashumancia”. En R. García Martín (ed.): Por los caminos de la Trashumancia. Junta de Castilla y León. León: 149-158.

Celestino Pérez, S. 2001: Estelas de guerrero y estelas diademadas: la precolonización y formación del mundo tartésico. Bellaterra. Barcelona.

Celestino Pérez, S.; Mayoral Herrera, V.; Salgado Carmona, J. A. y Cazorla Martín, R. 2011: "Stelae Iconography and Landscape in South-west Iberia". En T. Moore y X-L. Armada (eds.): Atlantic Europe in the first millennium BC: crossing the divide. Oxford University Press. Oxford: 135-152.

Celestino Pérez, S.; Rafel, N. y Armada, X. L. (eds.) 2008: Contacto cultural entre el Mediterráneo y el Atlántico (siglos XII-VIII ane). La precolonización a debate. Consejo Superior de Investigaciones Científicas. Madrid.

Chapman, R. W. 1979: "Transhumance and megalithic tombs in Iberia". Antiquity 53 (208): 150-151. https://doi.org/10.1017/s0003598x00109214

Chen, S. S. 2010: "Quantifying Landscape Connectivity: A GIS-based Approach". International Journal of Civil and Environmental Engineering 4 (10): 291-298.

Criado Boado, F. 1997: Del terreno al espacio: planteamientos y perspectivas para la Arqueología del Paisaje (CAPA 6). Universidad de Santiago de Compostela. Santiago de Compostela.

Criado Boado, F.; Fábregas Valcarce, R. y Vaquero Lastres, X. 19901991: "Concentraciones de túmulos y vías naturales de acceso al interior de Galicia”. Portugalia. Nova Série XI-XII: 27-38.

Criado Boado, F. y Vaquero Lastres, J. 1993: "Monumentos, nudos en el pañuelo. Megalitos, nudos en el espacio: Análisis del emplazamiento de los monumentos tumulares gallegos". Espacio, Tiempo y Forma, Serie I 6: 205-248.

Delgado, A. 2013: "Households, Merchants and Feasting. Socioeconomic Dynamics and Commoners' Agency in the Emergence of the Tartessian World (Eleventh to Eighth Centuries B.C.)". En M. Cruz Berrocal, L. García Sanjuán y A. Gilman (eds.): The Prehistory of Iberia. Debating early social stratification and the state. Routledge. New York: 311-336.

Delibes de Castro, G.; Moreno Gallo, M. A.; Villalobos, R. y Basconcillos, J. 2012: Piedra Alta. El guardián del tiempo. Diputación de Burgos. Burgos

Delibes de Castro, G. y Romero Carnicero, F. 1992: "El último milenio a.C. en la Cuenca del Duero. Reflexiones sobre la secuencia cultural". En M. Almagro-Gorbea y G. Ruiz Zapatero (eds.): Paleoetnología de la Península Ibérica. Complutum Extra 2-3, Editorial Complutense. Madrid: 233-258.

Delibes de Castro, G. y Romero Carnicero, F. 2011: "La plena colonización agraria del Valle Medio del Duero". En J. R. Álvarez-Sanchís, A. Jimeno Martínez y G. Ruiz Zapatero (eds.): Aldeas y ciudades en el primer milenio a.C. La Meseta Norte y los origenes del urbanismo. Complutum Extra 22-2, Editorial Complutense. Madrid: 49-94.

Díaz-del-Río, P. 1995: "Campesinado y gestión pluriactiva del ecosistema: un marco teórico para el análisis del III y II milenios a.C. en la
Meseta peninsular". Trabajos de Prehistoria 52 (2): 99-109. https://doi.org/10.3989/tp.1995.v52.i2.420

Díaz-del-Río, P. 2001: La formación del paisaje agrario. Madrid en el III y II milenios $B C$. Comunidad de Madrid. Madrid.

Díaz-del-Río, P.; Waterman, A. J.; Thomas, J. T.; Peate, D. W.; Tykot, R. H.; Martínez-Navarrete, M. I. y Vicent, J. M. 2017: "Diet and mobility patterns in the Late Prehistory of central Iberia (4000-1400 cal $\mathrm{BC})$ : the evidence of radiogenic $\left({ }^{87} \mathrm{Sr} /{ }^{86} \mathrm{Sr}\right)$ and stable $\left(\delta^{18} \mathrm{O}, \delta^{13} \mathrm{C}\right)$ isotope ratios". Archaeological and Anthropological Sciences 9: 1439-1452. https://doi.org/10.1007/s12520-017-0480-y

Díaz-Guardamino Uribe, M. 2010: Las estelas decoradas en la prehistoria de la Península Ibérica. Universidad Complutense. Madrid. https://eprints.ucm.es/11070/

Esparza Arroyo, A. 1999: "Economía de la Meseta prerromana". Studia Histórica. Historia Antigua 17: 87-123.

Eve, S. J. y Crema, E. R. 2014: "A house with a view? Multi-model inference, visibility fields, and point process analysis of a Bronze Age settlement on Leskernick Hill (Cornwall, UK)". Journal of Archaeological Science 43: 267-277. https://doi.org/10.1016/j.jas.2013.12.019

Fairén Jiménez, S.; Cruz Berrocal, M.; López-Romero, E. y Walid Sbeinati, S. 2006: "Las vías pecuarias como elementos arqueológicos". En I. Grau Mira (ed.): Territorios antiguos y nuevas tecnologías. La aplicación de los SIG en la arqueología del paisaje. Universidad de Alicante. Alicante: 55-68.

Fernández-Mier, M. y Tente, C. 2018: "Transhumant herding systems in Iberia”. En E. Costello y E. Svensson (eds.): Historical archaeologies of transhumance across Europe. Routledge. London: 119-232.

Fernández-Posse, M. ${ }^{a}$ D. 1998: La investigación protohistórica en la Meseta y Galicia. Síntesis. Madrid.

Galán Domingo, E. 1993: Estelas, paisaje y territorio en el Bronce Final del Suroeste de la Península Ibérica. Complutum Extra 3, Universidad Complutense de Madrid. Madrid.

Galán Domingo, E. y Ruiz-Gálvez, M. 2001: "Rutas ganaderas, trasterminancia y caminos antiguos. El caso del Occidente Peninsular entre el Calcolítico y la Edad del Hierro". En J. Gómez-Pantoja (ed.): Los rebaños de Gerión. Pastores y trashumancia en Iberia antigua y medieval. Casa de Velázquez. Madrid: 279-311.

Galaty, J. C. y Johnson, J. D. 1990: "Introduction - Pastoral Systems in Global Perspective”. En J. C. Galaty y J. D. Johnson (eds.): Pastoral Systems in Global Perspective. Guilford Press. New York: 1-67.

García Martín, P. 1991: Cañadas, cordeles y veredas. Junta de Castilla y León. Valladolid.

García Sanjuán, L. 1999: Los orígenes de la estratificación social. Patrones de desigualdad en la Edad del Bronce del suroeste de la Península Ibérica (Sierra Morena occidental c. 1700-1100 ane/21001300 ANE). British Archaeological Reports, International Series 823, Archaeopress. Oxford.

García Sanjuán, L.; Wheatley, D. W.; Fábrega Álvarez, P.; Hernández Arnedo, M. J. y Polvorinos del Río, A. 2006: 'Las estelas de guerrero de Almadén de la Plata (Sevilla). Morfología, tecnología y contexto". Trabajos de Prehistoria 63 (2): 135-152. https://doi.org/10.3989/tp.2006.v63.i2.21

Gilman, A. 1993: "Cambio cultural y contacto en la prehistoria de la Europa mediterránea". Trabajos de Prehistoria 50: 103-111. https://doi.org/10.3989/tp.1993.v50.10.491

Gilman, A. 1995: "Prehistoric European Chiefdoms. Rethinking 'Germanic' Societies". En T. D. Price y G. M. Feinman (eds.): Foundations of social inequality. Plenum Press. New York: 235-251.

González Cordero, A. 2015: "La Edad de Bronce en el Campo Arañuelo". XXI Coloquios histórico-culturales del Campo Arañuelo. Ayuntamiento de Navalmoral de la Mata. Navalmoral de la Mata: 107-158.

Greenfield, H. J. 1999: "Introduction”. En L. Bartosiewicz y H. J. Greenfield (eds.): Transhumant pastoralism in Southern Europe: recent perspectives from Archaeology, History, and Ethnography. Archaeolingua Publishers. Budapest: 9-12.

Harrison, R. J. 1994: "The Bronze Age in Northern and Northeastern Spain 2000-800 BC". En C. Mathers y S. Stoddart (eds.): Development and decline in the Mediterranean Bronze Age. University of Sheffield. Sheffield: 73-97. 
Harrison, R. J. 2004: Symbols and warriors: images of the European Bronze Age. Western Academic \& Specialist Press Ltd. Bristol.

Horden, P. y Purcell, N. 2000: The corrupting sea: a study of Mediterranean History. Blackwell. Oxford.

Hurtado Pérez, V.; García Sanjuán, L. y Hunt Ortiz, M. A. (eds.) 2011: El asentamiento de El Trastejón (Huelva). Investigaciones en el marco de los procesos sociales y culturales de la Edad del Bronce en el Suroeste de la Península Ibérica. Junta de Andalucía. Sevilla.

Infante Roura, F.; Vaquero Lastres, J. y Criado Boado, F. 1992: "Vacas, caballos, abrigos y túmulos: definición de una geografía del movimiento para el estudio arqueológico". Cuadernos de Estudios Gallegos XL (105): 21-39. https://doi.org/10.3989/ceg.1992.v40.i105.297

Jimeno Martínez, A. 2001: "El modelo de trashumancia aplicado a la cultura de Cogotas I”. En M. Ruiz-Gálvez (ed.): La Edad del Bronce, ¿primera Edad de Oro en España?: sociedad, economía e ideología. Crítica. Barcelona: 139-180.

Lancelotti, C.; Balbo, A.; Madella, M.; Iriarte, E.; Rojo, M.; Royo, I.... y Peña Chocarro, L. 2014: "The missing crop: investigating the use of grasses at Els Trocs, a Neolithic cave site in the Pyrenees $(1564 \mathrm{~m}$ asl)". Journal of Archaeological Science 42: 456-466. https://doi. org/10.1016/j.jas.2013.11.021

Liesau, C. 2016: "Some prestige goods as evidence of interregional interactions in the funerary practices of the Bell Beaker groups of Central Iberia". En E. Guerra Doce y C. Liesau (eds.): Analysis of the economic foundations supporting the social supremacy of the Beaker Groups. Archaeopress. Oxford: 69-94

Logemann, E.; Kalkbrenner, G.; Schüle, W. y Krützfeldt, B. 1995: "Contenido de mercurio en huesos de animales domésticos y trashumancia". En V. M. O. Jorge (ed.): $1^{\text {er }}$ Congresso de Arqueologia Peninsular (Porto 1993) VI: 457-465. Porto.

López-Plaza, M.; Esparza Arroyo A.; García Gómez, I. y López-Moro, F. J. 2018: "Procedencia del material pétreo de los molinos de los yacimientos Cogotas I (Bronce Medio y Tardío) de la Cuenca del Duero y modelos consecuentes de flujo". Estudios Geológicos, 74 (1), e074. http://doi.org/10.3989/egeol.42955.462

López-Sáez, J. A.; Blanco-González, A.; Abel-Schaad, D.; Robles-López, S.; Luelmo-Lautenschlaeger, R.; Pérez-Díaz, S. y Alba-Sánchez, F. 2018: "Transhumance dynamics in the Gredos Range (central Spain) during the last two millennia. Environmental and socio-political vectors of change". En E. Costello y E. Svensson (eds.): Historical archaeologies of transhumance across Europe. Routledge. Oxford: 233-244.

Lozny, L. R. (ed.) 2013: Continuity and change in cultural adaptation to mountain environments. from Prehistory to contemporary threats. Springer. New York.

Makarewicz, C. A. y Sealy, J. 2015: "Dietary reconstruction, mobility, and the analysis of ancient skeletal tissues: expanding the prospects of stable isotope research in archaeology". Journal of Archaeological Science 56: 146-58. https://doi.org/10.1016/j.jas.2015.02.035

Mangas Navas, J. M. 1992: Vias pecuarias. Instituto para la Conservación de la Naturaleza. Madrid.

Mitrović, S. 2016: Connectivity: an ecological paradigm for the study of Bronze Age. City University of New York. New York. https://academicworks.cuny.edu/gc_etds/690/ (consulta febrero 2018).

Mlekuž, D. 2005: "The ethnography of the Cyclops: Neolithic pastoralists in the eastern Adriatic". Documenta Praehistorica 32: 15-51. https://doi.org/10.4312/dp.32.2

Molina González F. y Pareja López, E. 1975: Excavaciones en la Cuesta del Negro (Purullena, Granada), campaña 1971. Excavaciones Arqueológicas de España 86, Ministerio de Educación Nacional. Madrid.

Murrieta-Flores, P. 2010: "Travelling in a prehistoric landscape: Exploring the influences that shaped human movement". En J. Frischer, J. W. Crawford y D. Koller (eds.): Making history interactive. Computer applications and quantitative methods in Archaeology (CAA). Proceedings of the $37^{\text {th }}$ International Conference (Williamsburg, Virginia, United States of America 2009). British Archaeological Reports, International Series 2079. Archaeopress. Oxford: 258-276.

Murrieta-Flores, P. 2012: "Understanding human movement through spatial technologies. The role of natural areas of transit in the Late
Prehistory of South-western Iberia”. Trabajos de Prehistoria 69 (1): 103-122. https://doi.org/10.3989/tp.2012.12082

Murrieta-Flores, P. 2014: "Space and Temporality in Herding Societies: Exploring the Dynamics of Movement during the Iberian Late Prehistory". En S. Souvatzi y A. Hadji (eds.): Space and time in Mediterranean Prehistory. Routledge. New York: 196-213.

Murrieta-Flores, P.; García Sanjuán, L. y D. W. Wheatley 2014: "Modelando la movilidad y el movimiento a través de los SIG. Estudios de caso en la Prehistoria Reciente de Sierra Morena occidental". En E. García Alfonso (ed.): Movilidad, cambio y contacto. II Congreso de Prehistoria de Andalucía (Antequera 2012): 77-92. Sevilla.

Murrieta-Flores, P.; Wheatley, D. W. y García Sanjuán, L. 2011: "Movilidad, trashumancia y paisaje prehistórico: Estudio del paisaje arqueológico de Almadén de la Plata, Andalucía a través de un SIG". En V. Mayoral Herrera y S. Celestino Pérez (eds.): Tecnologías de información geográfica y análisis arqueológico del territorio. Actas del V Simposio Internacional de Arqueología de Mérida (Mérida 2007). Anejos del Archivo Español de Arqueología LIX, CSICJunta de Extremadura. Mérida: 411-423.

Pavón Soldevila, I.; Duque Espino, D. M.; Sanabria Murillo, D. y Collado Giraldo, H. 2018. "La estela de 'Cabeza del Buey V/El Palacio' en el poblamiento de la Edad del Bronce de la sierra de Tiros (Badajoz)". Spal 27 (1): 31-60. https://doi.org/10.12795/spal.2018i27.02

Renfrew, C. 1986: "Introduction: peer polity interaction and socio-political change". En C. Renfrew y J. F. Cherry (eds.): Peer polity interaction and socio-political change. Cambridge University Press. Cambridge: 1-18.

Rodríguez Díaz, A. y Enríquez Navascués, J.-J. 2001: Extremadura tartésica. Arqueología de un proceso periférico. Bellaterra. Barcelona.

Rodríguez Díaz, A.; Pavón Soldevila, I. y Duque Espino, D. M. 2015: "Jerarquía y heterarquía en las cuencas extremeñas del Guadiana y Tajo durante el Período Orientalizante". En M. C. Belarte, D. Garcia y J. Sanmartí (eds.): Les estructures socials protohistòriques a la Gàl-lia i a Ibèria. Homenatge a Aurora Martín i Enriqueta Pons. Aqueomediterrània 14, Barcelona: 295-313.

Rojo-Guerra, M. A.; Arcusa, H.; Peña-Chocarro, L.; Royo, J. I.; Tejedor, C.; García, I.... y Alt, K. W. 2014: "Los primeros pastores trashumantes de la Alta Ribagorza". Sobrarbe antes de Sobrarbe: pinceladas de historia de los Pirineos. Instituto de Estudios Altoaragoneses. Huesca: 127-151.

Rojo-Guerra, M. A.; Peña Chocarro, L.; Royo Guillén, J. I.; Tejedor Rodríguez, C.; García Martínez de Lagrán, I.; Arcusa Magallón, H.... y Alt, K. W. 2013: "Pastores trashumantes del Neolítico Antiguo en un entorno de alta montaña: secuencia crono-cultural de la Cova de Els Trocs (San Feliú de Veri, Huesca)". Boletín del Seminario de Estudios de Arte y Arqueología - Arqueología LXXIX: 9-56.

Ruiz-Gálvez, M. 1993: "El occidente de la Península Ibérica, punto de encuentro entre el Mediterráneo y el Atlántico a fines de la Edad del Bronce". Complutum 4: 41-68.

Ruiz-Gálvez, M. 1998: La Europa Atlántica en la Edad del Bronce. Un viaje a las raices de la Europa occidental. Crítica. Barcelona.

Ruiz-Gálvez, M. 1999: “Ancient routes and modern motorways: a lasting tradition of communications in the Iberian Peninsula from the Bronze Age onwards". En C. Orrling (ed.): Symposium Communication in Bronze Age Europe. Transactions of the Bronze Age. Tanumstrand, Bohuslän (Sweden 1995). Statens Historiska Museum. Sweden: 8192.

Ruiz-Gálvez, M. 2013: Con el fenicio en los talones. Los inicios de la Edad del Hierro en la cuenca del Mediterráneo. Bellaterra. Barcelona.

Ruiz-Gálvez, M. y Galán Domingo, E. 1991: "Las estelas del suroeste como hitos de vías ganaderas y rutas comerciales". Trabajos de Prehistoria 48: 257-273. https://doi.org/10.3989/tp.1991.v48.i0.524

Ruiz Martín, F. y García Sanz, A. (eds.) 1998: Mesta, trashumancia y lana en la España moderna. Crítica. Barcelona.

Ruiz Zapatero, G. 2007: "Antes del Hierro. Cultura y sociedad en el centro de la Meseta (ca. 1200-500 a.C.)". En A. F. Dávila (ed.): Estudios sobre la Edad del Hierro en la Carpetania. Zona Arqueológica 10, 1, Comunidad de Madrid. Madrid: 36-62.

Trab. Prehist., 76, N. ${ }^{\circ}$ 1, enero-junio 2019, pp. 67-83, ISSN: 0082-5638

https://doi.org/10.3989/tp.2019.12226 
Sánchez Moreno, E. 1998: "De ganados, movimientos y contactos. Revisando la cuestión trashumante en la protohistoria hispana: la Meseta occidental". Studia Historica. Historia Antigua 16: 53-84.

Sánchez-Polo, A. 2011: "Aproximación espacial a una composición decorativa en cerámicas de Cogotas I”. En J. P. López García, D. Hernández Sánchez y J. García Sánchez (eds.): Los vínculos entre el hábitat y el paisaje. Actas del I Congreso de Arqueología de Chamartín (Ávila 2010). La Ergástula. Madrid: 105-116.

Souvatzi, S. y Hadji, A. (eds.) 2014: Space and time in Mediterranean Prehistory. Routledge. New York.

Taylor, P.; Fahrig, L.; Henein, K. y Merriam, G. 1993: "Connectivity is a vital element of landscape structure". Oikos 68: 571-573. https://doi.org/10.2307/3544927

Vilaça, R. 1995: Aspectos do povoamento da Beira Interior (Centro e Sul) nos finais da Idade do Bronze. Instituto Português do Património Arquitectónico. Lisboa.

Vilaça, R. 1998: "Hierarquizaçào e conflito no Bronze Final da Beira Interior”. En S. O. Jorge (ed.): Existe uma Idade do Bronze Atlàntico? Instituto Português de Arqueologia. Lisboa: 203-217.

Walker, M. J. 1983: "Laying a Mega-Myth: Dolmens and Drovers in Prehistoric Spain". World Archaeology. Transhumance and Pastoralism 1 (15): 37-50. https://doi.org/10.1080/00438243.1983.9979883
Walsh, K. 2014: The Archaeology of Mediterranean landscapes. Humanenvironment interaction from the Neolithic to the Roman period. Cambridge University Press. Cambridge.

Wheatley, D. W.; García Sanjuán, L.; Murrieta-Flores, P. y Márquez Pérez, J. 2010: "Approaching the landscape dimension of the megalithic phenomenon in Southern Spain". Oxford Journal of Archaeo$\operatorname{logy} 29$ (4): 387-405. https://doi.org/10.1111/j.1468-0092.2010.00354.x

Yubero-Gómez, M.; Rubio-Campillo, X.; López-Cachero, F. J. y EsteveGràcia, X. 2015: "Mapping changes in late prehistoric landscapes: a case study in the Northeastern Iberian Peninsula". Journal of Anthropological Archaeology 40: 123-134. https://doi.org/10.1016/j.jaa.2015.07.002

\section{ANEXO}

En la versión electrónica de este artículo, disponible en libre acceso en la página web de la revista, se incluyen en el PDF como anexo la localización y listado de sitios de Cogotas I. 


\section{Conectividad en la Edad del Bronce del occidente de la península ibérica. Examinando la relación entre sitios y vías pecuarias mediante SIG}

Connectivity in Bronze Age Western Iberia. Appraising the relationship between sites and droveways using GIS

Antonio Blanco González y Ángel Esparza Arroyo

Material suplementario

Supplementary material 


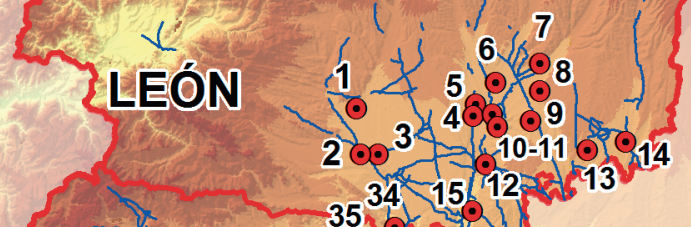

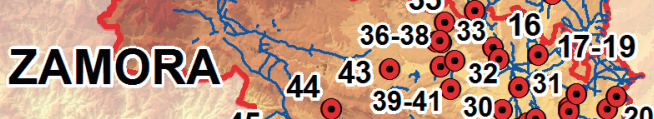

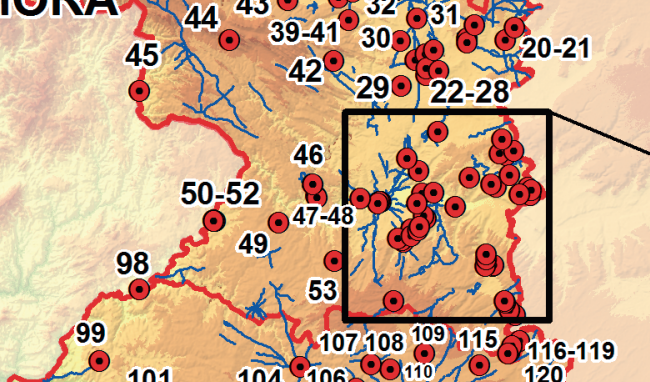

in $101-104106-120$

100,102 f 105 (122)

$3 \gamma_{102}^{103}$

SALAMANCA $\quad 1135.131-132$

1.20126

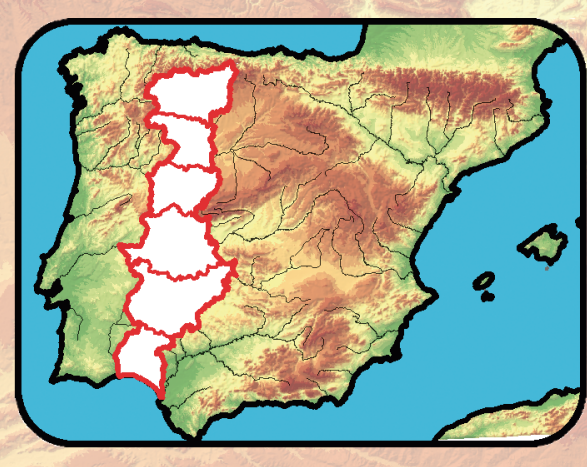

$\int x^{2} \leq 140 \% 137-138$

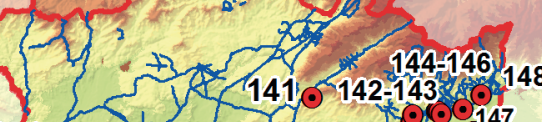

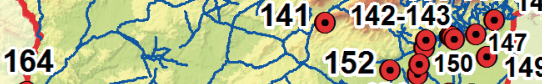

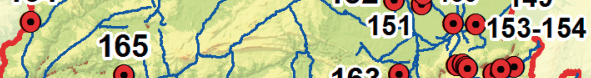

CACERES

BADAJOZ

.

(०) 17-175

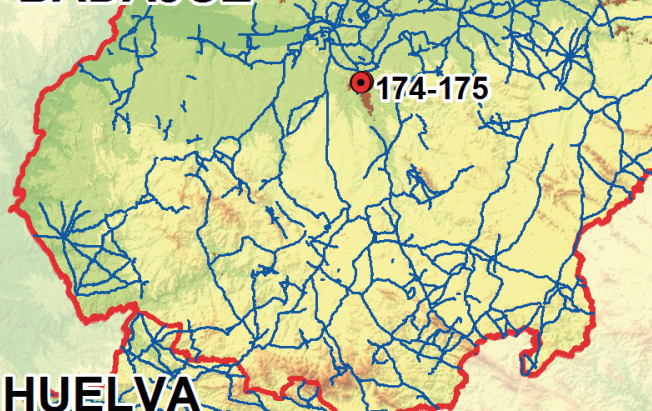

HUELVA

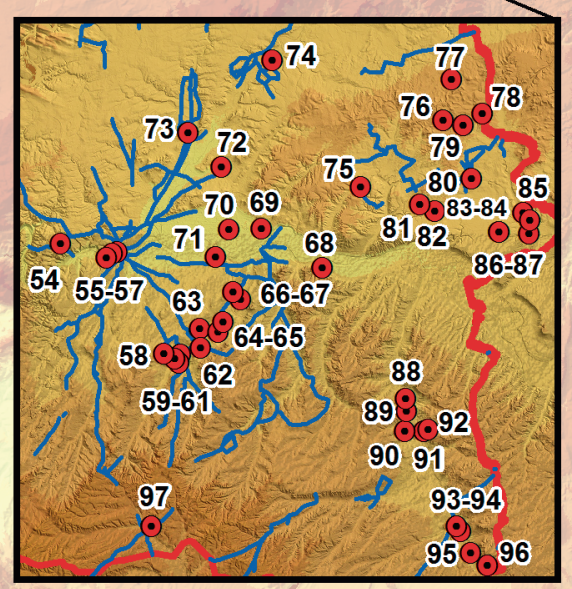

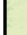


Listado de sitios:

1. El Morión (Posadilla, León); 2. Sacaojos (Santiago de la Valduerna, León); 3. El Castro (Regueras, León); 4. El Castro (Ardón, León); 5. El Castillo (Ardón, León); 6. El Molino (Roderos, León); 7. La Senada (Valle de Mansilla, León); 8. Camino de la Toza (Reliegos, León); 9. Los Castros (Santas Martas, León); 10. Las Vegas (Jabares de los Oteros, León); 11. Las Lentejeras (Velilla, León); 12. El Castillo (Valencia de Don Juan, León); 13. Fuente de la Salud (Villeza, León); 14. Canto Blanto (Calzada del Coto, León); 15. El Pelambre (Villaornate, León); 16. Morales de las Cuevas (Fuentes de Ropel, Zamora); 17. El Tejar (Cerecinos, Zamora); 18. La Boyana (Cerecinos, Zamora); 19. Los Molarinos (Villalobos, Zamora); 20. Los Pedregales (Villardefallaves, Zamora); 21. Los Hitos (Villamayor de Campos, Zamora); 22. Santioste (Otero de Sariegos, Zamora); 23. Valorio (Villafáfila, Zamora); 24. Teso del Marqués (Villafáfila, Zamora); 25. Teso de Santa Catalina (Villafáfila, Zamora); 26. La Cantera (Villafáfila, Zamora); 27. El Torrejón (Villafáfila, Zamora); 28. El Cementerio (Villafáfila, Zamora); 29. La Facima (Manganeses de la Polvorosa, Zamora); 30. Los Tesos (Santovenia, Zamora); 31. Los Cenizales (Bercial, Zamora); 32. Requejo (Santa Cristina de la Polvorosa, Zamora); 33. La Corona (Manganeses de la Polvorosa, Zamora); 34. La Vizana (Alija del Infantado, Zamora); 35. Las Labradas (Arrabalde, Zamora); 36. San Adrián (Granucillo de Vidriales, Zamora); 37. Las Peñezuelas (Granucillo de Vidriales, Zamora); 38. La Vega (Granucillo de Vidriales, Zamora); 39. Fioba (Sitrama de Tera, Zamora); 40. Las Viñas (Santibáñez de Tera, Zamora); 41. Los Villares (Morales de Valverde, Zamora); 42. Los Centelanes (Tábara, Zamora); 43. El Cerillico (Calzadilla de Tera, Zamora); 44. El Castillo (Cabañas de Aliste, Zamora); 45. El Pedroso (San Martín de El Pedroso, Zamora); 46. San Esteban (Muelas del Pan, Zamora); 47. El Vedal (Castil de la Cabra, Zamora); 48. Castil de la Cabra (Muelas del Pan, Zamora); 49. El Montico (Abelón, Zamora); 50. El Castrilluzo (Fariza, Zamora); 51. El Castillo (Fariza, Zamora); 52. Las Fraguas (Cozcurrita, Zamora); 53. La Modorra (Mogátar, Zamora); 54. Valdelaloba (Zamora); 55. Casco antiguo (Zamora); 56. San Francisco Sabuloso (Zamora); 57. Teso del Castro (Zamora); 58. Las Carretas (Casaseca de las Chanas, Zamora); 59. Pozoblanco (Cazurra, Zamora); 60. El Rabiao II (Cazurra, Zamora); 61. Las Raposeras (Cazurra, Zamora); 62. Los Mimbrerales (Gema, Zamora); 63. Los Chanos (Casaseca de las Chanas, Zamora); 64. La Perrona (Moraleja del Vino, Zamora); 65. San Martín (Moraleja del Vino, Zamora); 66. Los Verdiales (Bamba, Zamora); 67. La Horca (Madridanos, Zamora); 68. El Chafaril (Pelagonzalo, Zamora); 69. El Tomillar (Fresno de la Ribera, Zamora); 70. Laguna de Don García (Coreses, Zamora); 71. El Juncal (Villaralbo, Zamora); 72. Las Reguerinas (Algodre, Zamora); 73. La Muela (Torres del Carrizal, Zamora); 74. Valdivieso (Aspariegos, Zamora); 75. Cerro de San Miguel (Pozoantiguo, Zamora); 76. La Arcilla (Pinilla de Toro, Zamora); 77. Los Molinos (Vezdemarbán, Zamora); 78. Los Villares (Pinilla de Toro, Zamora); 79. El Puentón (Pinilla de Toro, Zamora); 80. Los Centenales (Villavendimio, Zamora);

81. El Poleo (Tagarabuena, Zamora); 82. El Palomar (Tagarabuena, Zamora); 83. El Moralino (Morales de Toro, Zamora); 84. Los Moralinos (Morales de Toro, Zamora); 85. El Cementerio (Morales de Toro, Zamora); 86. El Soto (Morales de Toro, Zamora); 87. El Pinar (Morales de Toro, Zamora); 88. Los Lavaderos (Villabuena del Puente, Zamora); 89. La Olla (Villabuena del Puente, Zamora); 90. La Ermita (La Bóveda de Toro, Zamora); 91. Carracastro I (La Bóveda de Toro, Zamora); 92. Carracastro II (La Bóveda de Toro, Zamora); 93. La Rinconada (Vadillo de la Guareña, Zamora); 94. Gómez Arias (Vadillo de la Guareña, Zamora); 95. La Encina (Castrillo de la Guareña, Zamora); 96. El Decimal (Castrillo de la Guareña, Zamora); 97. El Chagaril (Cubo del Vino, Zamora); 98. Virgen del Castillo (Pereña, Salamanca); 99. Peñas de la Noria (Barruecopardo, Salamanca); 100. Picón del Rey (Cerralbo, Salamanca); 101. Las Cañadas (Guadramiro, Salamanca); 102. Yecla la Vieja (Yecla de Yeltes, Salamanca); 103. Los Quemados (Aldehuela de la Bóveda, Salamanca); 104. Plaza de San Martín (Ledesma, Salamanca); 105. Valdecidiel (Barbadillo, Salamanca); 106. El Regado (Pino de Tormes, Salamanca); 107. Teso del Cuerno (Forfoleda, Salamanca); 108. Las Cabrillas (Calzada de Valdunciel, Salamanca); 109. Rayaespino (Tardáguila, Salamanca); 110. La Septa (Castellanos de Moriscos, Salamanca); 111. Cerro de San Vicente (Salamanca); 112. Los Claudios (Salamanca); 113. El Soto (Calvarrasa de Arriba, Salamanca); 114. El Palomar (Aldealengua, Salamanca); 115. El Castillo (Espino de la Orbada, Salamanca); 116. Las Guadañas (Olmo de la Guareña, Salamanca); 117. Valdemoro (Olmo de la Guareña, Salamanca); 118. Las Obispalías (Olmo de la guareña, Salamanca); 119. Las Calderonas (Olmo de la Guareña, Salamanca); 120. Las Barceras (Poveda de las Cintas, Salamanca); 121. La Calzada (Campo de Peñaranda, Salamanca); 122. La Aceña (Huerta, Salamanca); 123. El Priorato (Paradinas de San Juan, Salamanca); 124. Tordillos (Aldeaseca de la Frontera, Salamanca); 125. Peña Blanca (Bóveda del Río Almar, Salamanca); 126. La Rúa (Bóveda del Río Almar, Salamanca); 127. Los Hornos (Coca de Alba, Salamanca); 128. Las Ollas (Garciherández, Salamanca); 129. Castillo de Carpio (Carpio Bernardo, Salamanca); 130. Los Pinares (Santiago de la Puebla, Salamanca); 131. Castañeda (Villagonzalo de Tormes, Salamanca); 132. Las Laderas (Herrezuelo, Salamanca); 133. El Bejarano (Martinamor, Salamanca);

Trab. Prehist., 76, N. ${ }^{\circ}$ 1, enero-junio 2019, pp. 67-83, ISSN: 0082-5638

https://doi.org/10.3989/tp.2019.12226 
134. Bercimuelle (Galisancho, Salamanca); 135. Tierras de Garri (La Maya, Salamanca); 136. Coto Alto (La Tala, Salamanca); 137. La Dehesa (El Tejado, Salamanca); 138. Cancho Enamorado (El Tejado, Salamanca); 139. La Corvera (Navalmoral de Béjar, Salamanca); 140. El Tranco del Diablo (Béjar, Salamanca); 141. La Villavieja (Plasencia, Cáceres); 142. La Salud (Collado, Cáceres); 143. Mesillas II (Jarandilla de la Vera, Cáceres); 144. El Baldío (Jarandilla de la Vera, Cáceres); 145. El Cincho (Jarandilla de la Vera, Cáceres); 146. Lomas del Medio (Talayuela, Cáceres); 147. El Centenillo (Tiétar, Cáceres); 148. Cuesta de los Pinos II (Villanueva de la Vera, Cáceres); 149. Arroyo de los Huertos (Rosalejo, Cáceres); 150. Cuarto de Mata (Tayuela, Cáceres); 151. El Pedazo (Casatejada, Cáceres); 152. Arroyo del Caño (Majadas de Tiétar, Cáceres); 153. Polígono Industrial (Navalmoral de la Mata, Cáceres); 154. La Aguada (Navalmoral de la Mata, Cáceres); 155. La Mata (Berrocalejo, Cáceres); 156. Talavera la Vieja (Peraleda de San Román, Cáceres); 157. Barrera de la Zamorana (Bohonal de Ibor, Cáceres); 158. La Muralla (Valdehuncar, Cáceres); 159. Cueva de los Canchones (Valdehuncar, Cáceres); 160. Cañadilla II (Valdehuncar, Cáceres); 161. El Higuerón (Valdehuncar, Cáceres); 162. El Pibor (Mesas de Ibor, Cáceres); 163. Alija (Peraleda de San Román, Cáceres); 164. Peñafiel (Zarza la Mayor, Cáceres); 165. Canchal de Potro Nuevo (Portezuelo, Cáceres); 166. Cabeza de Araya (Navas del Madroño, Cáceres); 167. Aguijón de Pantoja (Trujillo, Cáceres); 168. Maltravieso (Cáceres); 169. El Risco (Sierra de Fuentes, Cáceres); 170. Cerro de la Horca (Plasenzuela, Cáceres); 171. Los Castillejos (Robledillo, Cáceres); 172. San Cristóbal (Valdemorales, Cáceres); 173. El Carrascalejo (El Carrascalejo, Badajoz); 174. El Castillo-Solana (Alange, Badajoz); 175. El Castillo-Umbría (Alange, Badajoz); 176. El Trastejón (Zufre, Huelva). 